OPEN ACCESS

Edited by:

Mattijs Julsing,

Technical University of Dortmund,

Germany

Reviewed by:

Shawn Chen,

Revive Genomics Inc., USA

Markus Nett,

Technical University of Dortmund,

Germany

*Correspondence:

Carmen Méndez

cmendezf@uniovi.es.

Specialty section:

This article was submitted to Microbiotechnology, Ecotoxicology

and Bioremediation,

a section of the journal

Frontiers in Microbiology

Received: 06 October 2016

Accepted: 26 January 2017

Published: 10 February 2017

Citation:

Ye S, Molloy B, Braña AF, Zabala $D$, Olano C, Cortés J, Morís F, Salas JA

and Méndez C (2017) Identification

by Genome Mining of a Type I

Polyketide Gene Cluster from

Streptomyces argillaceus Involved

in the Biosynthesis of Pyridine and Piperidine Alkaloids Argimycins P.

Front. Microbiol. 8:194.

doi: 10.3389/fmicb.2017.00194

\section{Identification by Genome Mining of a Type I Polyketide Gene Cluster from Streptomyces argillaceus Involved in the Biosynthesis of Pyridine and Piperidine Alkaloids Argimycins $\mathbf{P}$}

\author{
Suhui Ye ${ }^{1}$, Brian Molloy ${ }^{1}$, Alfredo F. Braña ${ }^{1}$, Daniel Zabala ${ }^{1}$, Carlos Olano ${ }^{1}$, \\ Jesús Cortés ${ }^{2}$, Francisco Morís ${ }^{2}$, José A. Salas ${ }^{1}$ and Carmen Méndez ${ }^{1 *}$ \\ ${ }^{1}$ Departamento de Biología Funcional e Instituto Universitario de Oncología del Principado de Asturias, Universidad de \\ Oviedo, Oviedo, Spain, ${ }^{2}$ EntreChem, S.L, Oviedo, Spain
}

Genome mining of the mithramycin producer Streptomyces argillaceus ATCC 12956 revealed 31 gene clusters for the biosynthesis of secondary metabolites, and allowed to predict the encoded products for 11 of these clusters. Cluster 18 (renamed cluster arp) corresponded to a type I polyketide gene cluster related to the previously described coelimycin P1 and streptazone gene clusters. The arp cluster consists of fourteen genes, including genes coding for putative regulatory proteins (a SARPlike transcriptional activator and a TetR-like transcriptional repressor), genes coding for structural proteins (three PKSs, one aminotransferase, two dehydrogenases, two cyclases, one imine reductase, a type II thioesterase, and a flavin reductase), and one gene coding for a hypothetical protein. Identification of encoded compounds by this cluster was achieved by combining several strategies: (i) inactivation of the type I PKS gene arpPIII; (ii) inactivation of the putative TetR-transcriptional repressor arpRIl; (iii) cultivation of strains in different production media; and (iv) using engineered strains with higher intracellular concentration of malonyl-CoA. This has allowed identifying six new alkaloid compounds named argimycins $P$, which were purified and structurally characterized by mass spectrometry and nuclear magnetic resonance spectroscopy. Some argimycins $\mathrm{P}$ showed a piperidine ring with a polyene side chain (argimycin PIX); others contain also a fused five-membered ring (argimycins PIV-PVI). Argimycins PI-PIl showed a pyridine ring instead, and an additional $N$-acetylcysteinyl moiety. These compounds seem to play a negative role in growth and colony differentiation in S. argillaceus, and some of them show weak antibiotic activity. A pathway for the biosynthesis of argimycins $\mathrm{P}$ is proposed, based on the analysis of proposed enzyme functions and on the structure of compounds encoded by the arp cluster.

Keywords: cryptic, type I polyketide synthase, pyridine, piperidine, thioester reductase, growth, alkaloid, Streptomyces 


\section{INTRODUCTION}

Natural products have been a productive source of bioactive compounds and drugs. By the mid-1990s, $>50 \%$ of all new drugs were either natural products or analogs (Cragg et al., 1997). This frequency has decreased since then, due to the increased efforts in synthetic small molecules, while the isolation and characterization of new natural products from crude extracts remains perceived as time-consuming and labor-intensive. However, natural products and their analogs still account for $>40 \%$ of small molecule drugs under development (Newman and Cragg, 2016). The importance of drug development based on natural products and their analogs is, in part, associated with their structural diversity, which facilitates opening up unexplored chemical spaces (Bauer et al., 2010). The growing appreciation of functional assays and phenotypic screens may further contribute to a revival of interest in natural products for drug discovery (Harvey et al., 2015).

Streptomycetes are Gram-positive bacteria with high GC DNA content that are mainly found in terrestrial and aquatic environments, and show a complex development cycle, involving formation of substrate and aerial mycelium, and spores (Flärdh and Buttner, 2009; Barka et al., 2016). Moreover, they are one of the most important sources of microbial bioactive compounds. These compounds are secondary metabolites that show, among others, antibiotic, antifungal, antiparasitic, immunosuppressive or herbicide activities. In addition, some of them also play a role in colony development in these microorganisms (Barka et al., 2016). Most bioactive compounds belong to the polyketide, peptide, hybrid polyketide-peptide and terpene groups. Polyketides (PK) are synthesized by macroenzyme complexes called polyketide synthases (PKS) through the condensation of small acyl-CoA units. Three different types of PKS have been described so far. Type I or modular PKS are typically organized into modules, each one responsible for a single elongation cycle. Each module contains a $\beta$-ketoacyl synthase (KS), an acyltransferase (AT) and an acyl carrier protein (ACP) domain. AT domains select the appropriate acyl-CoA unit that will be used in the corresponding extension cycle; KS domains are responsible for the decarboxylative Claisen condensations of acyl-CoA units; ACPs are non-catalytic domains that tether the growing PK chain and building block on its phosphopantetheine arm. After every condensation step, the resulting $\beta$-keto group of the biosynthesis intermediate could be modified before the next elongation step by functional domains optionally present in the corresponding module: ketoreductase (KR), dehydratase $(\mathrm{DH})$, and enoyl reductase (ER). KRs stereospecifically reduce the carbonyl group of the $\beta$-ketoacyl-ACP intermediates leading to the formation of a $\beta$-hydroxyl group; DH domains catalyze reversible dehydration events to yield double bond formation between the $\alpha$ - and $\beta$-carbons in the polyketide chain; ER domains catalyze the reduction of double bonds to form fully reduced methylene in the carbon chain (Hertweck, 2009; Weissman, 2015).

Novel compounds are still needed to address uncovered medical needs, like infectious diseases, or cancer. Natural products possess desirable structural and chemical properties that make suitable as potent drugs, but steep technological challenges associated with screening and manufacturing of these molecules has stifled the discovery and development of natural products. The recent development of genomics, metagenomics and high-throughput screening has increased exponentially the volume of useful genetic sequence information that can be employed for natural products discovery. Additionally, a new manufacturing paradigm employing metabolic engineering and synthetic biology as its engine has greatly accelerated the path of development for microbial natural product drugs (Rutledge and Challis, 2015; Katz and Baltz, 2016; Pawar et al., 2016). Genome mining consists of searching a genome for genes that encode enzymes involved in a particular process. In recent years, genome mining has been applied to streptomycetes and has become a new and quick approach to identify previously unknown gene clusters (Olano et al., 2014; Rutledge and Challis, 2015; Ochi, 2016). In most cases these clusters are silent or lowly expressed under laboratory conditions. Therefore, several strategies have been developed to awake and/or increase their expression, and to identify the compounds encoded by these gene clusters, which involve both the use of genetic engineering approaches and the use of different media and culture conditions (Olano et al., 2014; Rutledge and Challis, 2015; Ochi, 2016).

In this paper we report the genome mining of Streptomyces argillaceus ATCC 12956, a producer of the known antitumoral drug mithramycin, and the use of this approach to uncover cryptic pathways, lowly or not expressed by the wild type strain. One of these pathways lowly expressed under standard laboratory conditions, has been overexpressed and the products isolated and characterized chemically and biologically, namely the argimycin $P$ family of compounds.

\section{MATERIALS AND METHODS}

\section{Bacterial Strains, Culture Conditions, Plasmids and DNA Manipulations}

Streptomyces argillaceus ATCC 12956, and S. argillaceus GIH, $S$. argillaceus AFTA and $S$. argillaceus AFTA-GIH (Zabala et al., 2013) were used as source of DNA and for gene replacement and expression experiments, and/or production of argimycins P. For sporulation the strains were grown for 7 days at $30^{\circ} \mathrm{C}$ on agar plates containing medium $\mathrm{A}$ (Fernández et al., 1998). Streptomyces sp. NRRL S-1022 was used to test argimycins P production. SM10 and SM17 media were used for argimycins P production by S. argillaceus and Streptomyces S-1022, respectively. When required, antibiotics were added to media at the following final concentrations: ampicillin $(100 \mu \mathrm{g} / \mathrm{mL})$, kanamycin $(50 \mu \mathrm{g} / \mathrm{mL})$, nalidixic acid $(25 \mu \mathrm{g} / \mathrm{mL})$, apramycin $(25 \mu \mathrm{g} / \mathrm{mL})$, and thiostrepton $(50 \mu \mathrm{g} / \mathrm{mL})$. A pKC505-based cosmid library of $S$. argillaceus genome DNA was used to identify cosmids containing arp genes (Lombó et al., 1996). Escherichia coli DH10B (Invitrogen) and E. coli ET12567/pUB307 (Kieser et al., 2000) were used as cloning hosts for plasmid propagation and for conjugation experiments, respectively. Antibiotic activity of argimycins $\mathrm{P}$ was assayed against Micrococcus luteus, Escherichia coli and Saccharomyces 
cerevisiae, as described Vilches et al. (1990). Plasmids pCRBlunt (Invitrogen) and pUO9090 (M. C. Martín, unpublished results), were used for subcloning. Plasmids pHZ1358 (Sun et al., 2002) and pBSKTT (this work) were used for generating mutants by gene replacement and gene disruption. pEM4ATC (C. Cano-Prieto, unpublished results) and pIAGO (Aguirrezabalaga et al., 2000) were used for gene expression in S. argillaceus. pBSKTT was constructed by cloning a PstI fragment containing the oriT from pEM4T (Menéndez et al., 2006), into the PstI site of pBSKT (Lombó et al., 1999). DNA manipulations, transformations and intergeneric conjugations were performed according to standard procedures for E. coli (Sambrook and Russell, 2001) and for Streptomyces (Kieser et al., 2000). Herculase (Stratagene) and 2.5\% dimethyl-sulfoxide (DMSO) were used for PCR amplifications. Purified amplicons were sequenced and compared to others in databases.

\section{Sequencing and Analysis of DNA}

Streptomyces argillaceus genome DNA sequence was obtained by Life Sequencing (Valencia, Spain; pyrosequencing 454 Life Science-Roche platform). Paired end sequences were de novo assembled using the Newbler assembler v. 2.8 (Margulies et al., 2005). Sequence of cluster 18 was completed using PCR fragments (Sanger et al., 1977) (DNA sequencing service; University of Oviedo). Annotation was performed using PGAAP (Prokaryotic Genomes Automatic Annotation Pipeline) (Angiuoli et al., 2008). Database searching and sequence analysis were carried out using antiSMASH (Antibiotic and Secondary

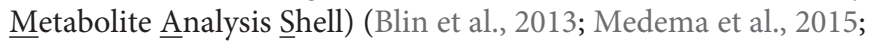
Weber et al., 2015), and BLAST (Altschul et al., 1997). Analysis of domains in PKS and NRPS were carried out using ASMPKS (Tae et al., 2007) and NRPS predictor (Rausch et al., 2005). Search for transmembrane domains was carried out using the TMHMM v.2.0 (Krogh et al., 2001).

\section{Plasmid Constructs for Gene Expression and Generating Mutants}

Several plasmids were generated as described in Supplementary Material, either to express arp genes or to generate mutants in S. argillaceus (Table 1). Mutants were generated by either disrupting the target gene by inserting a plasmid, or by replacing a DNA region by an apramycin resistance cassette that was inserted in the same direction of transcription. These plasmids were independently introduced by conjugation into S. argillaceus, and transconjugants were selected either with thiostrepton (pBSKTT-based plasmids) or with apramycin ( $\mathrm{pHZ1358-based}$ plasmids). In the last case, apramycin-resistance, thiostreptonsensitive colonies were selected. Mutants were confirmed by PCR amplification using specific oligonucleotides (Supplementary Table S1), and sequencing the PCR products.

\section{UPLC Analysis and Purification of Argimycins $\mathbf{P}$}

Culture samples $(1 \mathrm{ml})$ were extracted with 1 volume of $n$-butanol. Organic extracts were dried under vacuum, and residues were dissolved in a small volume of DMSO: methanol
(50:50). Analysis of argimycins $\mathrm{P}$ production was performed by reversed-phase chromatography on Acquity UPLC equipment with a BEH C18 column $(1.7 \mu \mathrm{m}, 2.1 \times 100 \mathrm{~mm}$; Waters, Milford, MA, USA) with acetonitrile and $0.1 \%$ trifluoroacetic acid (TFA) in water as eluent. Samples were eluted with $10 \%$ acetonitrile for $1 \mathrm{~min}$, followed by a linear gradient from 10 to $61.4 \%$ acetonitrile over $4 \mathrm{~min}$ at a flow rate of $0.5 \mathrm{ml} / \mathrm{min}$ and a column temperature of $30^{\circ} \mathrm{C}$. Detection and spectral characterization of peaks were carried out with a photodiode array detector and Empower software (Waters). Chromatograms were extracted at 400, 272, and $230 \mathrm{~nm}$.

For purification purposes, S. argillaceus MARPRII was grown by a two-step culture method, as previously described Fernández et al. (1998). In the production step, 40 250-milliliter Erlenmeyer flasks, each containing medium $(50 \mathrm{~mL})$, were incubated for 3 days. The cultures were centrifuged and filtered, and applied to a solid-phase extraction cartridge (Sep-Pak Vac C18, $10 \mathrm{~g}$, Waters). The retained material was eluted with a mixture of methanol and $0.1 \%$ TFA in water. A linear gradient from 0 to $100 \%$ methanol in $55 \mathrm{~min}$, at $5 \mathrm{ml} / \mathrm{min}$, was used. Fractions were taken every $5 \mathrm{~min}$, and analyzed by UPLC. Fractions containing the desired compounds were evaporated in vacuo, and dissolved in a small volume of a mixture of DMSO and methanol (50:50). Products were purified by preparative HPLC using a SunFire C18 column $(10 \mu \mathrm{m}, 10 \times 150 \mathrm{~mm}$, Waters $)$. Compounds were chromatographed with mixtures of acetonitrile and $0.1 \%$ TFA in water, in isocratic conditions optimized for each compound, at $5 \mathrm{ml} / \mathrm{min}$.

\section{Structural Characterization of Compounds}

LC/MS (liquid chromatography mass spectrometry) analyses were carried out on an Agilent 1200 Rapid Resolution HPLC

TABLE 1 | Mutant and recombinant S. argillaceus strains generated in this work.

\begin{tabular}{lll}
\hline Strains & Plasmid used & Gene(s)* \\
\hline Mutant strains & & \\
MARPN & pHZMutAT & arpN \\
MARPPII & pBSKTT1701 & arpPIII \\
MARPRI & pHZMutSARP & arpRI \\
MARPRII & pHZMutTetR & arpRII \\
MORF3 & pHZMutorf3 & orf3 \\
MORF4 & pHZMutorf17 & orf4 \\
MORF9 & pHZMutNAcTr & orf9 \\
DARPO-HII & pHZDel59b & arpO, arpDHI, arpDHII, arpN, \\
& arpK, arpHI, arpHII \\
DORF5-7 & pHZDel1820 & orf5, orf6, orf7 \\
DORF11-16 & pHZDel13 & orf11, orf12, orf13, orf14, \\
& orf15, orf16 \\
DORF19-21 & pHZDel2 & orf19, orf20, orf21 \\
Recombinant strains & & \\
MARPPIII (pEM4ATCPKS) & pEM4ATCPKS & arpPII, arpT \\
DARPO-HII (plAGOorf8) & plAGOorf8bis & arpN \\
\hline
\end{tabular}

* Genes mutated or expressed. 
system equipped with a SB-C8 column $(2.1 \times 30 \mathrm{~mm}$, Zorbax $)$ and coupled to a Bruker maXis mass spectrometer. Samples were subjected to LC/ESI-TOF analysis in order to determine their molecular formula. For the Nuclear Magnetic Resonance (NMR) analysis samples were dissolved in deuterated methanol $\left(\mathrm{CD}_{3} \mathrm{OD}\right)$ and transferred to a $1.7 \mathrm{~mm}$ tube. Acquisitions were carried out on a Bruker AVANCE III $500 \mathrm{MHz}$ spectrometer equipped with a $1.7 \mathrm{~mm}$ TCI Microcryoprobe. All spectra were recorded at $297 \mathrm{~K}$. Structural elucidation of compounds was carried out by analysis of a combination of $1 \mathrm{D}\left({ }^{1} \mathrm{H}\right.$ and $\left.{ }^{13} \mathrm{C}\right)$, and $2 \mathrm{D}\left({ }^{1} \mathrm{H}-{ }^{1} \mathrm{H}\right.$ COSY, TOCSY, HSQC and HMBC) NMR experiments.

\section{Determination of Stereochemistry of Argimycins PI and PII}

A solution containing argimycins PI/PII was subjected to a desulfurization/reduction reaction using the method reported by Martin et al. (2004) with some modifications: a solution of argimycins PI and PII (1.0 mg) and nickel chloride $(2.0 \mathrm{mg})$ in $2.0 \mathrm{~mL}$ of $\mathrm{MeOH} / \mathrm{H}_{2} \mathrm{O}$ was added to a screwcap flask containing $\mathrm{NaBH}_{4}(2.0 \mathrm{mg})$ with immediate resealing of the reaction vial. A black precipitate, namely $\mathrm{Ni}_{2} \mathrm{~B}$, was immediately formed and the mixture stirred for $1 \mathrm{~h}$ at $50^{\circ} \mathrm{C}$. After centrifugation, the supernatant containing the released $N$-acetylalanine was recovered, evaporated to dryness and subjected to the Marfey's analysis (Marfey, 1984): $0.4 \mathrm{mg}$ of the reaction product were suspended in $1.0 \mathrm{~mL}$ of $12 \mathrm{~N} \mathrm{HCl}$ and heated at $110^{\circ} \mathrm{C}$ for $2 \mathrm{~h}$. The crude hydrolysate was evaporated to dryness under a nitrogen stream, and the residue was dissolved in $100 \mu \mathrm{L}$ of miliQ $\mathrm{H}_{2} \mathrm{O}$. A $1 \%(\mathrm{w} / \mathrm{v})$ solution $(100 \mu \mathrm{L})$ of L-FDVA [N-(2,4-dinitro-5fluorophenyl)-valinamide] in acetone was added. After addition of $20 \mu \mathrm{L}$ of $1 \mathrm{M} \mathrm{NaHCO}_{3}$ solution, the mixture was incubated at $40^{\circ} \mathrm{C}$ for $60 \mathrm{~min}$. The reaction was quenched by addition of $10 \mu \mathrm{L}$ of $1 \mathrm{~N} \mathrm{HCl}$, and the crude mixture was diluted with $700 \mu \mathrm{L}$ of acetonitrile and analyzed by LC/MS on an Agilent 1100 single quadrupole. Similarly, the standards of L- and D-alanine were also separately derivatized L-FDVA, according to the method mentioned above. Separations were carried out on an Agilent Zorbax SB-C8 column $(2.1 \times 30 \mathrm{~mm}, 3.5 \mu \mathrm{m})$ maintained at $40^{\circ} \mathrm{C}$. A mixture of two solvents, A (10\% acetronitrile, $90 \%$ water) and $\mathrm{B}$ (90\% acetonitrile, $10 \%$ water), both containing $1.3 \mathrm{mM}$ trifluoroacetic acid and $1.3 \mathrm{mM}$ ammonium formiate, was used as the mobile phase under a linear gradient elution mode (10-40\% B in $11 \mathrm{~min}$, then $100 \% \mathrm{~B}$ ) at a flow rate of $0.3 \mathrm{~mL} / \mathrm{min}$.

\section{RESULTS}

\section{Genome Mining of Streptomyces argillaceus ATCC 12956 Genome}

Streptomyces argillaceus ATCC 12956 genomic DNA was subjected to 454 sequencing, yielding 512,452 paired end sequences with a mean of $340.62 \mathrm{nt}$ (174.55 Mb total). De novo assembly of these sequences resulted in 1538 contigs, 1330 of which were larger than 500 nucleotides. The N50 of the contig assembly was around $10.5 \mathrm{~Kb}$, being the largest around
68.1 Kb. Most of these contigs were ordered in 20 scaffolds: the N50 of the scaffolding was $1.2 \mathrm{Mb}$ and the largest scaffold was $3.5 \mathrm{Mb}$. This combination of scaffolds and contigs resulted in an estimated genome size of $10.7 \mathrm{Mb}$. Genome analysis led to the annotation of 7638 coding sequences, 4 rRNAs and 66 tRNAs. Sequence analysis with antiSMASH (Blin et al., 2013; Medema et al., 2015; Weber et al., 2015) predicted the existence of 31 biosynthetic gene clusters (BGCs), including five for PKs, two for non-ribosomal peptides (NRPs), three for hybrid PKNRPs, seven for ribosomally synthesized and post-translationally modified peptides (RiPPs) and four for terpenes (Table 2).

Among PK clusters, there are two for type II PKS: cluster 6 corresponds to the already characterized mithramycin gene cluster (Lombó et al., 2006); and cluster 8 most probably is involved in the biosynthesis of a spore pigment. At the time of analysis, no prediction was available for compounds encoded by type I (clusters 18 and 23) and type III (cluster 3) PK clusters. The PK-NRP cluster 27 was predicted to be involved in antimycin biosynthesis, since it shows strong similarity to antimycin clusters

TABLE 2 | Secondary metabolite gene clusters identified in S. argillaceus by genome mining.

\begin{tabular}{|c|c|c|}
\hline Cluster & Type & Predicted product \\
\hline 1 & Butyrolactone & Unknown \\
\hline 2 & Thiopeptide & Lactazole-like \\
\hline 3 & Type III PKS & Unknown \\
\hline 4 & Other & Unknown \\
\hline 5 & Other & Unknown \\
\hline 6 & Oligosaccharide-Type II PKS & Mithramycin \\
\hline 7 & Bacteriocin & Unknown \\
\hline 8 & Type II PKS & Putative spore pigment \\
\hline 9 & NRPS & Unknown \\
\hline 10 & Ectoine & Hidroxyectoine \\
\hline 11 & TransAT-PKS-NRPS & Unknown \\
\hline 12 & Melanin & Melanin \\
\hline 13 & Siderophore & Desferrioxamine \\
\hline 14 & NRPS & Unknown \\
\hline 15 & Terpene & Albaflavenone \\
\hline 16 & Lantipeptide & Unknown \\
\hline 17 & Siderophore & Unknown \\
\hline 18 & Type I PKS & Argimycins $\mathrm{P}^{(\mathrm{a})}$ \\
\hline 19 & Bacteriocin & Unknown \\
\hline 20 & Butylolactone-terpene & Gamma-butyrolactone/geosmine \\
\hline 21 & Siderophore & Unknown \\
\hline 22 & Terpene & Hopene \\
\hline 23 & Type I PKS & Unknown \\
\hline 24 & Bacteriocin & Unknown \\
\hline 25 & Melanin & Melanin \\
\hline 26 & Terpene & Isorenieratene \\
\hline 27 & PKS-NRPS & Antimycins \\
\hline 28 & Lantipeptide-NRPS & Unknown \\
\hline 29 & Lantipeptide & Unknown \\
\hline 30 & Other & Unknown \\
\hline 31 & PKS-NRPS & Unknown \\
\hline
\end{tabular}

(a) this work; PKS, polyketide synthase; NRPS, non-ribosomal peptide synthetase. 


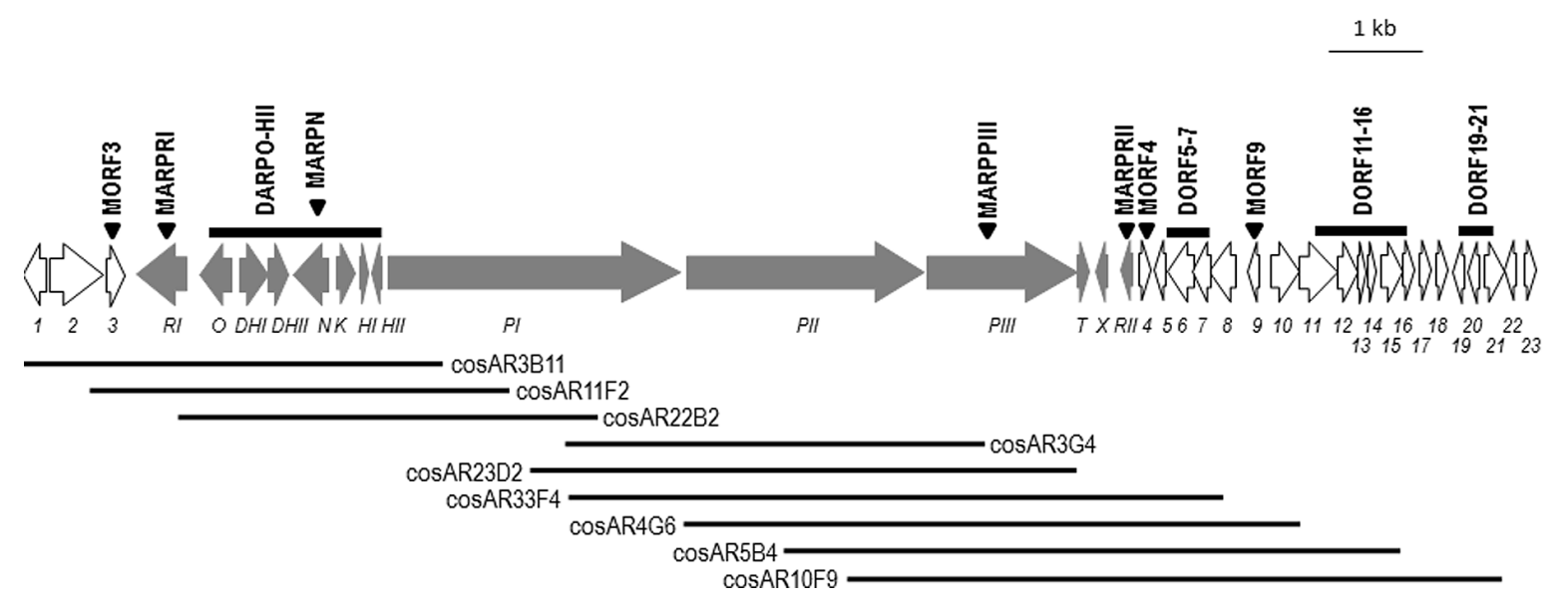

FIGURE 1 | Genetic organization of cluster 18. Genes are shown to scale. Argimycins P biosynthesis genes (arp) are shown in gray. Other genes are shown in white and are numbered. Triangles indicate those genes that have been inactivated. Bars indicated DNA regions that have been deleted. Black lines represent overlapping cosmids isolated from this chromosomal DNA region.

that are highly conserved in other microorganisms (Seipke et al., 2011), while no assumption could be done for the PK-NRP clusters 11 and 31. Based on the strong similarities to other terpene biosynthesis gene clusters, cluster 15 was predicted to code for albaflavenone, described in S. coelicolor (Zhao et al., 2008); cluster 20 contains homologous genes to sabRAS, involved in gamma-butyrolactone biosynthesis in S. acidiscabies (Healy et al., 2009), and a geosmine synthase homologous gene that has been reported to be the only gene required for geosmine biosynthesis (Cane et al., 2006); cluster 22 was similar to hopene biosynthesis gene clusters (Ghimire et al., 2015); and cluster 26 would code the isorenieratene carotenoid (Takano et al., 2005). Some other clusters showed similarity to already known clusters, which has allowed predicting the corresponding biosynthesis products. For example, cluster 2 might be involved in the biosynthesis of a lactazole thiopeptide, similar to that described in S. lactacystinaeus (Hayashi et al., 2014). Also, cluster 10 would code for hydroxyectoine, described in other organisms such as S. chrysomallus (Prabhu et al., 2004); and cluster 13 that contains all genes required for the biosynthesis of siderophore desferrioxamine, described in S. coelicolor (Barona-Gómez et al., 2004). On the other hand, some of the clusters showed high similarity to very well conserved clusters, the metabolic products of which are not known. This is the case of cluster 9 (NRPs), and clusters 17 and 21 (NRPS-independent siderophores).

\section{Analysis of Cluster 18 and Identification of Encoded Compounds}

Among the $31 \mathrm{~S}$. argillaceus identified clusters, cluster 18 was selected for further characterization. This cluster spanned $68.295 \mathrm{~kb}$ and contained 37 open reading frames (orf), including three coding for a type I PKS, seven for regulatory genes and several for tailoring enzymes (Figure 1; Table 3). According to Table 3, ArpPI to ArpPIII PKS show strongest homology to the three PKS from the streptazone E biosynthesis gene cluster (Ohno et al., 2015). Co-linearity of cluster 18 was confirmed using PCR probes from different DNA regions of the cluster, to identify overlapping cosmids from an $S$. argillaceus gene library, followed by sequencing the ends of DNA inserts in these cosmids (Figure 1). Sequence of this cluster has been deposited at the European Nucleotide Archive (EBI-ENA) under the accession number LT615255, and at MIBIG under the accession number BGC0001433.

To identify the biosynthesis product(s) of this cryptic gene cluster, two approaches were followed in parallel: (i) Generation of a mutant in a PKS gene. To completely block the biosynthesis pathway directed by cluster 18, the PKS gene arpPIII was disrupted by inserting pBSKTT1701 into this gene, generating mutant MARPPIII (Table 1; Supplementary Figure S1); (ii) Inactivation of the putative tet $R$-like transcriptional repressor gene $\operatorname{arpRII}$. Cluster 18 contains seven putative transcriptional regulatory genes: two coding for SARP-like activators (orf1 and $\operatorname{arpRI)}$, two for Xre-like regulators (orf2 and orf22), one for a FMN binding repressor (orf7), and one for a tetR-like repressor $(\operatorname{arpRII})$. This last one $(\operatorname{arpRII)}$ was located two orfs downstream of PKS genes. Since TetR regulators usually behave as transcriptional repressors (Ramos et al., 2005), $\operatorname{arpRII}$ was inactivated to increase production of compounds encoded by the cluster, which will facilitate their identification. Using pHZMutTetR, most of arpRII was replaced by an apramycin resistance cassette generating mutant MARPRII (Table 1; Supplementary Figure S2).

Mutants MARPPIII and MARPRII (and the wild type strain as control) were cultivated in R5A medium to compare the metabolite profiles of these strains. Culture samples were harvested along growth and extracted with different solvents (ethyl acetate; ethyl acetate and $0.1 \%$ formic acid; $n$-butanol; or chloroform). Extracts were run by UPLC and chromatograms were obtained at 400, 272, and $230 \mathrm{~nm}$, and analyzed by identifying peaks that disappeared in MARPPIII and increased in MARPRII, in relation to the wild type strain. Chromatograms of $n$-butanol extracts showed differential peaks between strains 
(data not shown). Since the corresponding compounds were mostly produced in very low amounts, a media screening was conducted to increase their production levels. SM10 medium was selected as the best medium and was used thereafter. Figure 2 shows UPLC analysis of $n$-butanol extracts of MARPPIII and MARPRII cultivated in SM10, in comparison to those from the wild type strain. As it can be observed, inactivation of arpPIII (S. argillaceus MARPPIII) led to the disappearance of peaks present in the wild type strain: at $400 \mathrm{~nm}$ (Figure 2A, peaks I, II and N), $272 \mathrm{~nm}$ (Figure 2B, peaks IV, V and VI) and $230 \mathrm{~nm}$ (Figure 2C, peak IX). HPLC-MS analysis of the corresponding compounds revealed $\mathrm{m} / z$ values in positive mode of 331 for peaks I and II; 176 for peaks N and VI; 208 for peak IV; 192 for peak V; and 178 for peak IX. Detection of these compounds was recovered by expressing arpPIII (plus arpT) under the control of the erythromycin resistance promoter (pEM4ATCPKS), into MARPPIII (Figures 2A-C). On the other hand, inactivation of putative repressor gene arpRII (mutant MARPRII) led to a clear increase of production of most of these compounds (Figures 2A-C). From all these results it was deduced that compounds from those peaks were encoded by cluster 18. In addition, analysis of the three subunits of type I PKS encoded by cluster 18 suggested that the PK chain synthesized by this enzyme would result from the condensation of six malonyl-CoA units. Consequently, strains with higher intracellular concentration of malonyl-CoA should produce higher amounts of these compounds. Therefore, S. argillaceus GIH (overexpressing the acetyl-CoA carboxylase ovmGIH genes), S. argillaceus AFTA (a mutant in the acyl-CoA:diacylglycerol acyltransferase aftAa gene) and S. argillaceus AFTA-GIH (S. argillaceus AFTA overexpressing

\section{TABLE 3 | Functions of gene products from cluster 18.}

\begin{tabular}{|c|c|c|c|c|}
\hline Gene & aa & Proposed function & Similar protein (acc. number) & Identical aa (\%) \\
\hline Orf1 & 360 & SARP-like transcriptional regulator & WP_037724676.1 & 80 \\
\hline Orf2 & 773 & Xre-like transcriptional regulator & WP_061914503.1 & 80 \\
\hline Orf3 & 254 & Hypothetical protein & WP_031129425.1 & 81 \\
\hline ArpRI & 828 & SARP-like transcriptional regulator & WP_051790319.1 & 81 \\
\hline Arpo & 483 & Dehydrogenase & WP_030346790.1 & 87 \\
\hline ArpDHI & 392 & Dehydrogenase/hydroxylase & WP_030346791.1 & 96 \\
\hline ArpDHII & 293 & Imine reductase & WP_030346792.1 & 96 \\
\hline ArpN & 534 & Aminotransferase & WP_030346793.1 & 90 \\
\hline ArpK & 182 & Flavin reductase & WP_037814843.1 & 93 \\
\hline ArpHI & 137 & Cyclase & WP_030346795.1 & 95 \\
\hline ArpHII & 136 & Cyclase & WP_030346796.1 & 92 \\
\hline ArpPI & 4625 & Type I Polyketide Synthase & BAT51065.1 & 75 \\
\hline ArpPII & 3575 & Type I Polyketide Synthase & BAT51066.1 & 69 \\
\hline ArpPIII & 2203 & Type I Polyketide Synthase & BAT51067.1 & 73 \\
\hline ArpT & 257 & Type II thioesterase & WP_030348965.1 & 86 \\
\hline ArpX & 177 & Unknown & WP_031487542.1 & 88 \\
\hline ArpRII & 210 & TetR-like transcriptional repressor & WP_019065342.1 & 79 \\
\hline Orf4 & 215 & Reductase & WP_030993716.1 & 84 \\
\hline Orf5 & 126 & Hypothetical protein & WP_030579546.1 & 63 \\
\hline Orf6 & 381 & Oxidase & WP_024490800.1 & 75 \\
\hline Orf7 & 212 & Putative transcriptional repressor & WP_063624787.1 & 63 \\
\hline Orf8 & 381 & Monooxygenase & WP_051386635.1 & 63 \\
\hline Orf9 & 167 & $N$-acetyltransferase & WP_024490799.1 & 49 \\
\hline Orf10 & 406 & Cytochrome P450 & WP_024490798.1 & 82 \\
\hline Orf11 & 559 & AMP-dependent synthetase and ligase & WP_037777637.1 & 80 \\
\hline Orf12 & 285 & Hypothetical protein & WP_024490796.1 & 90 \\
\hline Orf13 & 170 & Thioesterase & WP_024490795.1 & 84 \\
\hline Orf14 & 96 & Acyl carrier protein & WP_052488578.1 & 65 \\
\hline Orf15 & 307 & Methyltransferase & WP_037777640.1 & 82 \\
\hline Orf16 & 291 & Thioesterase & WP_024490792.1 & 87 \\
\hline Orf17 & 234 & Phosphopantetheinyl transferase & WP_024490791.1 & 54 \\
\hline Orf18 & 208 & Pyrophosphorylase & WP_028437185.1 & 48 \\
\hline Orf19 & 137 & Dehydratase & WP_051387014.1 & 74 \\
\hline Orf20 & 134 & Thioesterase & WP_051387012.1 & 80 \\
\hline Orf21 & 333 & 3-oxoacyl-ACP synthase & WP_040020314.1 & 75 \\
\hline Orf22 & 161 & Xre-like transcriptional regulator & WP_024495143.1 & 77 \\
\hline Orf23 & 163 & LuxR-like transcriptional regulator & WP_061444915.1 & 63 \\
\hline
\end{tabular}


A

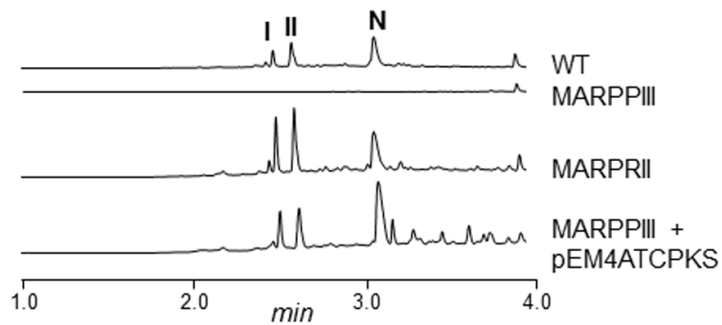

B

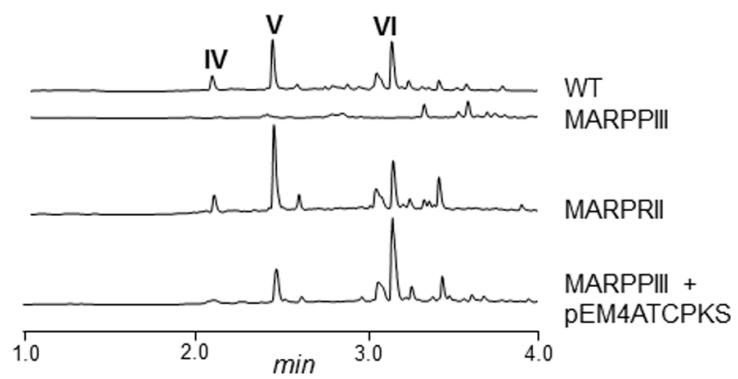

C

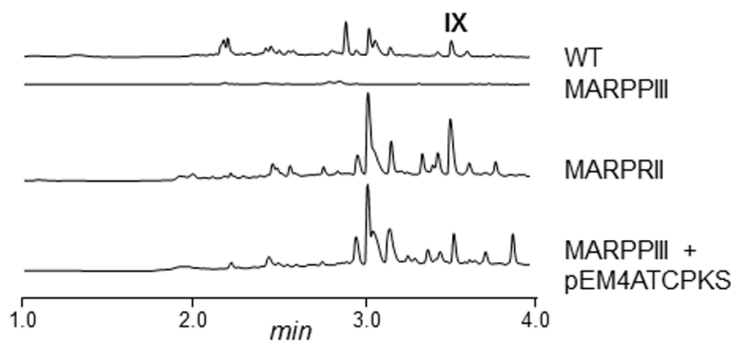

FIGURE 2 | UPLC chromatograms of S. argillaceus wild type and mutant strains in arp genes. Butanol extracts of $S$. argillaceus wild type strain (WT), S. argillaceus MARPPIII, S. argillaceus MARPRIII, and S. argillaceus MARPPIII (pEM4ATCPKS). Chromatograms are shown at $400 \mathrm{~nm}$ (A), $272 \mathrm{~nm}$ (B) and $230 \mathrm{~nm}$ (C). Peaks corresponding to the different argimycins $\mathrm{P}$ are indicated as follows: argimycins $\mathrm{PI}$ and $\mathrm{PII}(\mathbf{I}$ and $\mathbf{I I})$; nigrifactin (N); argimycin PIV (IV); argimycin PV (V); argimycin PVI (VI); and argimycin PIX (IX)

the acetyl-CoA carboxylase genes), which accumulate higher concentrations of malonyl-CoA (Zabala et al., 2013), were tested for production of compounds corresponding to peaks I and II (331 mass). As expected, higher production of these compounds was obtained with all strains, being the highest increases with S. argillaceus AFTA-GIH (Table 4).

\section{Purification, Structural Elucidation and Bioactivity of Compounds Encoded by Cluster 18}

Compounds from those peaks mentioned above were purified by preparative HPLC. Although peaks I and II were purified independently, they both correspond to a mixture of two main compounds that were present in different proportions. The major compound in peak I was named argimycin PI, and that in peak II argimycin PII. Moreover, there was a gradual interconversion of argimycin PII into argimycin PI and vice versa along time, till reach an equilibrium in which both compounds were present in the same proportion in both samples. Yields obtained for the different compounds were as follows: $3.5 \mathrm{mg}$ (peak I); $3.2 \mathrm{mg}$ (peak II); $3.9 \mathrm{mg}$ (peak $\mathbf{N}$, nigrifactin/named argimycin PIII); $8.8 \mathrm{mg}$ (peak IV, named argimycin PIV); $1.9 \mathrm{mg}$ (peak V, named argimycin PV); $0.9 \mathrm{mg}$ (peak VI, named argimycin PVI); and $1 \mathrm{mg}$ (peak IX, named argimycin PIX). The structure of these compounds, subsequently named argimycins PI-IX, were elucidated by NMR and MS analyses (Figure 3).

Argimycin PI shows a molecular formula $\mathrm{C}_{17} \mathrm{H}_{18} \mathrm{~N}_{2} \mathrm{O}_{3} \mathrm{~S}$ on the basis of the molecular ion $\mathrm{m} / z 331.1109$ obtained by ESITOF $\left([\mathrm{M}+\mathrm{H}]^{+}\right.$, calcd. for $\mathrm{C}_{17} \mathrm{H}_{19} \mathrm{~N}_{2} \mathrm{O}_{3} \mathrm{~S}^{+}$, 331.1116), that additionally displayed the typical isotope pattern for compounds that contain a sulfur atom. Sulfur has an isotopic distribution showing three isotopes, ${ }^{32} \mathrm{~S},{ }^{33} \mathrm{~S}$ and ${ }^{34} \mathrm{~S}$, with a ratio $100 / 0.8 / 4.5$. Therefore, compounds containing a sulfur atom show in their MS spectra an M+2 ion with an increased intensity with respect to non-sulfur containing molecules. Supplementary Figure S3 shows the experimental and simulated (for a molecular formula of $\mathrm{C}_{17} \mathrm{H}_{19} \mathrm{~N}_{2} \mathrm{O}_{3} \mathrm{~S}$ ) HRMS spectra of argimycin PI, indicating agreement with the presence of a sulfur atom in the molecule (not the case if the simulated formula was $\mathrm{C}_{17} \mathrm{H}_{19} \mathrm{~N}_{2} \mathrm{O}_{4}$ ). The same molecular formula was determined for argimycin PII, based on the observed molecular ion $\mathrm{m} / z 331.1112$ and the identical isotope pattern as argimycin PI. MS/MS experiments in ESI+ mode revealed, for both molecules, that the parent ion $\left(\mathrm{C}_{17} \mathrm{H}_{18} \mathrm{~N}_{2} \mathrm{~S}+\mathrm{H}^{+}\right)$generated a $\mathrm{C}_{12} \mathrm{H}_{12} \mathrm{NS}^{+}$fragment, and in turn, loss of $\mathrm{SH}_{2}$ provided the $\mathrm{C}_{12} \mathrm{H}_{10} \mathrm{~N}^{+}$ion. Fragmentation under ESI- conditions provided ion $[\mathrm{M}-\mathrm{H}]^{-}(\mathrm{m} / \mathrm{z} 329)$ as base peak, suggesting the presence of an acidic proton. NMR analysis (Table 5) showed 7 aromatic/olefinic protons, one methylene and one methine, both of them bound to heteroatom and two single methyl groups. Based on this data, together with the coupling constants from ${ }^{1} \mathrm{H}-\mathrm{NMR}$ and information from bidimensional COSY, HSQC, ${ }^{13} \mathrm{C}-\mathrm{HMBC}{ }^{15} \mathrm{~N}-\mathrm{HMBC}$ and NOESY, connectivity and stereochemistry of argimycin PI and PII was determined (Supplementary Figures S4-S11). Supplementary Figure S12 shows the signal assignments and the correlations observed by NOESY. For argimycin PII the NOESY experiment, which showed interaction between $\mathrm{H} 8$ and $\mathrm{H} 4$, while H9 interacts with $\mathrm{H} 6$ and Me-11, proved key to determine the correct stereochemistry of the double bonds (Supplementary Figure S13). The connectivity of the two isomeric argimycins PI and PII explains the results of the MS experiments. Under ESI- mode, both molecules ionize as $[\mathrm{M}-\mathrm{H}]-(\mathrm{m} / \mathrm{z} 329)$, in

TABLE 4 | Productions of peaks I and II in S. argillaceus strains containing higher intracellular concentration of malonyl-CoA.

\begin{tabular}{lcr}
\hline Strain & Peak $\mathbf{~ I}^{*}$ & \multicolumn{1}{c}{ Peak I** } \\
\hline WT & $43188 \pm 1871$ & $55614 \pm 2979$ \\
GIH & $55395 \pm 11477$ & $63914 \pm 9257$ \\
AFTA & $85358 \pm 4543$ & $102456 \pm 5311$ \\
AFTA-GIH & $151616 \pm 18711$ & $171609 \pm 7102$ \\
\hline
\end{tabular}

*Area of peaks, in arbitrary units. 


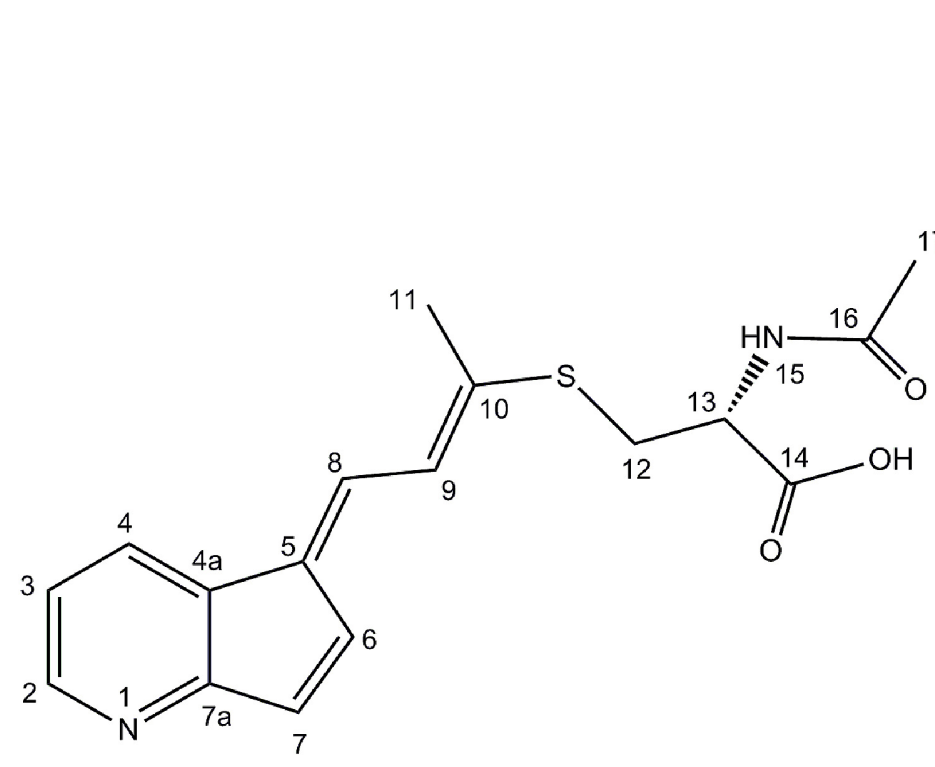

$\operatorname{argimycin} \mathbf{P I}$

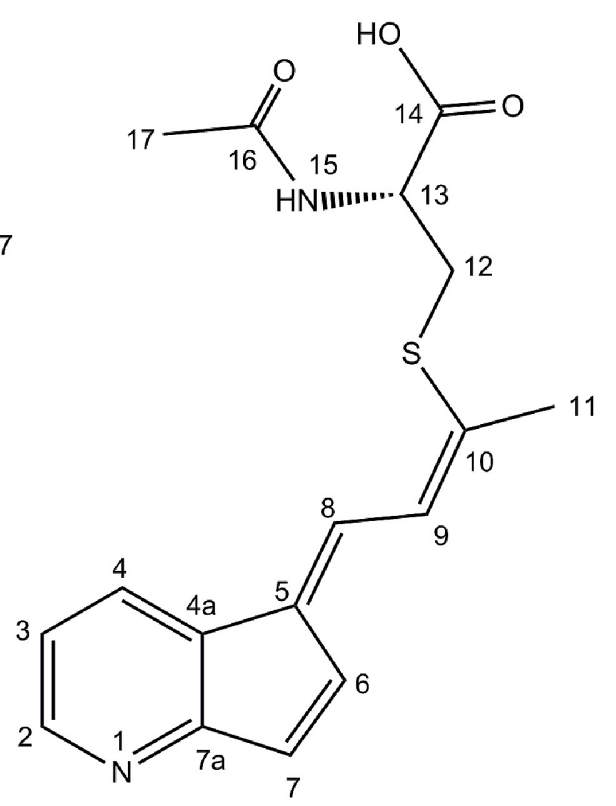

argimycin PII

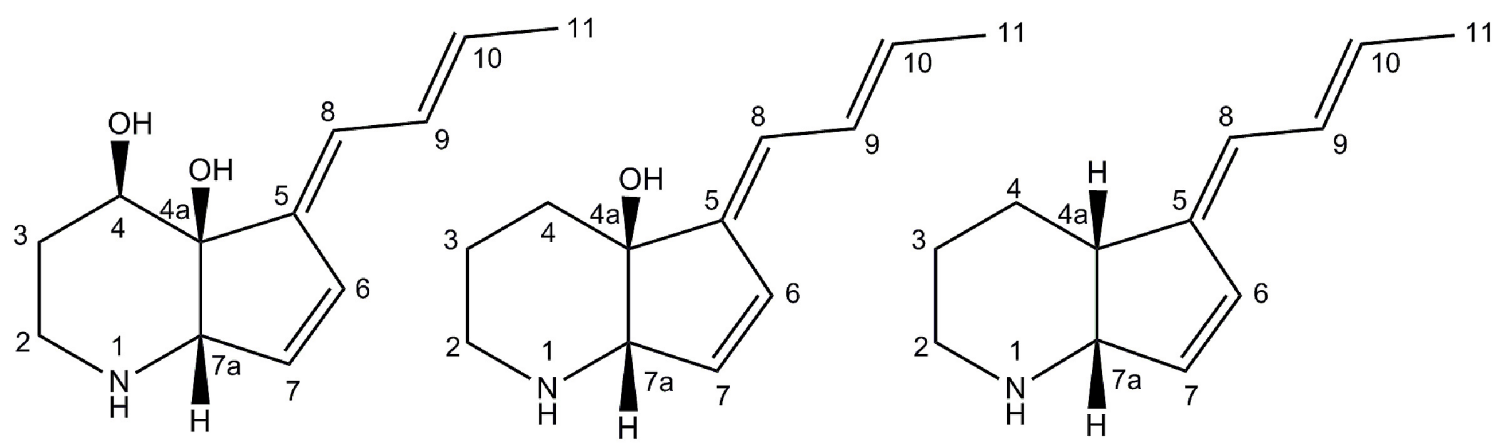

argimycin PIV argimycin PV argimycin PVI
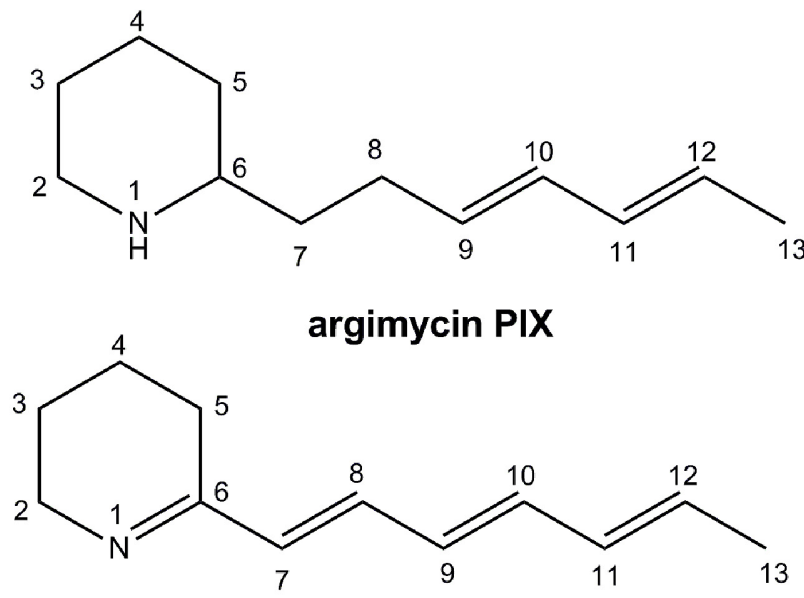

nigrifactin 
agreement with the carboxylic acid function. Also, under ESI-, a fragment $\mathrm{C}_{12} \mathrm{H}_{10} \mathrm{NS}^{-}(\mathrm{m} / z$ 200) is observed, which can be explained by a decarboxylation shown in Supplementary Figure S14. The stereochemistry of the $N$-acetylcysteine contained in these compounds was unambiguously established as ' $\mathrm{L}$ ' by means of a previous desulfurization/reduction reaction to release $N$-acetylalanine, and further hydrolysis and analysis of the released amino acid derivatized with L-FDVA. Under the reported conditions, the retention times $(\mathrm{min})$ for the derivatized alanine standards were 4.79 (L-Ala) and 6.87 (D-Ala), being the retention time for the observed peak in the HPLC trace of the L-FDVA derivatized hydrolysis product of argimycins PI/PII $4.78 \mathrm{~min}$, coincident with the retention time for L-Ala-L-FDVA (see Supplementary Figure S15).

Table 6 shows the NMR signal assignments for argimycin PIV, argimycin PV and argimycin PVI. Argimycin PV possesses a molecular formula of $\mathrm{C}_{12} \mathrm{H}_{17} \mathrm{NO}$, according to the base peak $m / z \quad 192.1383$ by ESI-TOF $\left([M+H]^{+}\right.$, calcd. for $\mathrm{C}_{12} \mathrm{H}_{18} \mathrm{NO}^{+}$, 192.1388). The ${ }^{1} \mathrm{H}-\mathrm{NMR}$ spectrum showed five olefinic protons and a methyl group signal, which was split into a doublet (Supplementary Figure S16). Comparative analyses using databases [Dictionary of Natural Products (DNP) NMR features] with the molecular formula and the structural characteristics mentioned, failed to dereplicate any possible candidate, hinting to the novelty of its structure. Together with bidimensional NMR and ${ }^{13} \mathrm{C}$-NMR spectra, the assignment provided in Table 6 was established (positions numerated as in argimycins PI and PII). Double bond relative stereochemistry for the ring fusion was

TABLE 5 | NMR data for argimycins PI-PII ( ${ }^{1} \mathrm{H}, 500 \mathrm{MHz} ;{ }^{13} \mathrm{C}, 150 \mathrm{MHz}$, in $\mathrm{CD}_{3} \mathrm{OD}$ )

\begin{tabular}{|c|c|c|c|}
\hline \multirow[b]{2}{*}{ Carbon } & \multicolumn{2}{|l|}{ Argimycin PI } & \multirow{2}{*}{$\begin{array}{l}\text { Argimycin PII } \\
\delta_{\mathrm{H}}(\text { mult, } J, \mathrm{~Hz})\end{array}$} \\
\hline & $\delta_{\mathrm{H}}$ (mult, J, Hz) & $\delta_{C}(p p m)$ & \\
\hline 2 & $8.30(d, 5.2)$ & 143.6 & $8.30(\mathrm{~d}, 5.2)$ \\
\hline 3 & $7.27(\mathrm{dd}, 7.7,5.2)$ & 119.2 & 7.24 (dd, 7.7, 5.2) \\
\hline 4 & $8.25(d, 7.7)$ & 127.9 & $8.12(d, 7.7)$ \\
\hline $4 a$ & - & 131.9 & - \\
\hline 5 & - & n.d. & - \\
\hline 6 & $7.67(d, 5.6)$ & 130.9 & $7.43(d, 5.6)$ \\
\hline 7 & $7.00(d, 5.6)$ & 127.4 & $6.98(d, 5.6)$ \\
\hline $7 a$ & - & 159.1 & - \\
\hline 8 & $7.69(\mathrm{~d}, 11.8)$ & 128.5 & $7.80(\mathrm{~d}, 11.8)$ \\
\hline 9 & $6.96(d, 11.8)$ & 117.3 & $7.03(\mathrm{~d}, 11.8)$ \\
\hline 10 & - & 148.2 & - \\
\hline 11 & $2.33(\mathrm{br} \mathrm{s}) 3 \mathrm{H}$ & 17.6 & $2.38(\mathrm{br} \mathrm{s}) 3 \mathrm{H}$ \\
\hline 12 & $\begin{array}{l}3.62(\mathrm{dd}, 13.0,4.6) \\
3.27(\mathrm{dd}, 13.0,7.7)\end{array}$ & 32.4 & $\begin{array}{l}3.49(\mathrm{dd}, 13.0,4.6) \\
3.23(\mathrm{dd}, 13.0,7.7)\end{array}$ \\
\hline 13 & $4.74(\mathrm{dd}, 7.7,4.7)$ & 52.1 & $4.61(\mathrm{dd}, 7.7,4.7)$ \\
\hline 14 & - & 172.3 & - \\
\hline 16 & - & 171.7 & - \\
\hline 17 & $2.01(\mathrm{~s}) 3 \mathrm{H}$ & 21.0 & 1.99 (s) $3 \mathrm{H}$ \\
\hline
\end{tabular}

\begin{tabular}{lc}
\hline Nitrogen & $\boldsymbol{\delta}_{\boldsymbol{N}}(\mathbf{p p m})$ \\
\hline 1 & 259.1 \\
15 & 121.9
\end{tabular}

established as cis (between the $\mathrm{OH}$ in $4 \mathrm{a}$ and the $\mathrm{H}$ in $7 \mathrm{a}$ ) by comparison with the chemical shifts and NOESY correlation profile observed for argimycin PVI, whose stereochemistry was unambiguously determined (see below).

Argimycin PVI possesses a molecular formula of $\mathrm{C}_{12} \mathrm{H}_{17} \mathrm{~N}$, according to the base peak $m / z 176.1433$ by ESI-TOF ([M+ $\mathrm{H}]^{+}$, calcd. for $\left.\mathrm{C}_{12} \mathrm{H}_{18} \mathrm{~N}^{+}, 176.1439\right)$. UV/vis spectrum shows a similar profile, including the maximum at $272 \mathrm{~nm}$, as in argimycin PV. Comparison of the ${ }^{1} \mathrm{H}-\mathrm{NMR}$ spectra for argimycin PV and argimycin PVI (Supplementary Figure S16) indicates that both molecules are structurally related, the difference in molecular formula suggests that argimycin PVI is the dehydroxy analog of argimycin PV. Dereplication based on molecular formula and NMR signals (DNP NMR features) failed to identify any previously described product, confirming the novelty of the structure. Bidimensional NMR spectra (Supplementary Figure S17) were acquired to elucidate the structure, assigning the signals unambiguously (Table 6). Double bond stereochemistry was established based on the coupling constants (identical profile as argimycin PV). NOESY spectrum showed a correlation between $\mathrm{H}-4 \mathrm{a}$ and $\mathrm{H}-7 \mathrm{a}$, confirming the fused ring cis stereochemistry.

Argimycin PIV possesses a molecular formula of $\mathrm{C}_{12} \mathrm{H}_{17} \mathrm{NO}_{2}$, according to the base peak $m / z 208.1334$ by ESI-TOF ([M+ $\mathrm{H}]^{+}$, calcd. for $\left.\mathrm{C}_{12} \mathrm{H}_{18} \mathrm{NO}_{2}{ }^{+}, 208.1338\right)$. UV/vis spectrum shows a similar profile, including the maximum at $272 \mathrm{~nm}$, as in argimycin PV and argimycin PIV. Comparison of the ${ }^{1} \mathrm{H}-\mathrm{NMR}$ spectra for argimycin PVI in $\mathrm{CD}_{3} \mathrm{OD}$ and DMSO$d_{6}$ showed that the former provides better signal resolution (Supplementary Figure S18), and $\mathrm{CD}_{3} \mathrm{OD}$ was selected for elucidation. This also facilitated comparison with argimycin PV and argimycin PVI (Supplementary Figure S19), which indicates that all three molecules are structurally related, the difference in molecular formula suggests that argimycin PIV is a hydroxylated analog of argimycin PV. As before, dereplication based on molecular formula and NMR signals (DNP NMR features) failed to identify any previously described product, confirming the novelty of the structure. Bidimensional NMR spectra (Supplementary Figure S20) were acquired to elucidate the structure, assigning the signals unambiguously (Table 6). Double bond stereochemistry was established based on the coupling constants (identical profile as argimycin PV). NOESY spectrum showed a correlation between $\mathrm{H}-4 \mathrm{a}$ and $\mathrm{H}-7 \mathrm{a}$, confirming the fused ring cis stereochemistry. Relative stereochemistry in C4 was established by the analysis of the coupling constant $J$ at $\mathrm{H} 4(\mathrm{dd}, 6.6 \mathrm{~Hz}, 3.0 \mathrm{~Hz}) .3 \mathrm{D}$ modeling (hydroxyls in relative cis position) shows dihedral angles $(\mathrm{H} 4-\mathrm{H} 3 \mathrm{a})=-170^{\circ}$ and $(\mathrm{H} 4-$ $\mathrm{H} 3 \mathrm{~b})=-55^{\circ}$, compatible with the observed $J$ values. On the other hand, the modeling of the epimer at $\mathrm{H} 4$ shows dihedral angles $(\mathrm{H} 4-\mathrm{H} 3 \mathrm{a})=-59^{\circ}$ and $(\mathrm{H} 4-\mathrm{H} 3 \mathrm{~b})=+59^{\circ}$, incompatible with the observed $J$ values (Supplementary Figure S21).

Argimycin PIII (nigrifactin) possesses a molecular formula of $\mathrm{C}_{12} \mathrm{H}_{17} \mathrm{~N}$, according to the base peak $m / z 176.1438$ by ESI-TOF $\left([\mathrm{M}+\mathrm{H}]^{+}\right.$, calcd. for $\left.\mathrm{C}_{12} \mathrm{H}_{18} \mathrm{~N}^{+}, 176.1439\right)$. UV/vis spectrum shows a different profile, including a maximum at $350 \mathrm{~nm}$. Comparison of the ${ }^{1} \mathrm{H}-\mathrm{NMR}$ spectra for argimycin PIII in $\mathrm{CD}_{3} \mathrm{OD}$ and DMSO- $d_{6}$ showed that the later provides better 
TABLE 6 | NMR data for argimycins PIV-PVI ( ${ }^{1} \mathrm{H}, 500 \mathrm{MHz} ;{ }^{13} \mathrm{C}, 150 \mathrm{MHz}$, in $\left.\mathrm{CD}_{3} \mathrm{OD}\right)$.

\begin{tabular}{|c|c|c|c|c|c|c|}
\hline \multirow[b]{2}{*}{ Carbon } & \multicolumn{2}{|c|}{ Argimycin PIV } & \multicolumn{2}{|c|}{ Argimycin PV } & \multicolumn{2}{|c|}{ Argimycin PVI } \\
\hline & $\delta_{H}$ (mult, J, Hz) & $\delta_{C}(p p m)$ & $\delta_{H}$ (mult, J, Hz) & $\delta_{C}(p p m)$ & $\delta_{H}$ (mult, J, Hz) & $\delta_{C}(p p m)$ \\
\hline \multirow[t]{2}{*}{2} & 3.27 (app quintet, ca. 6.3) & 35.5 & 3.18 (app quintet, ca. 6.3) & 39.1 & $3.13(\mathrm{~m})$ & 40.3 \\
\hline & 3.02 (app quintet, ca. 6.3) & & 3.07 (app quintet, ca. 6.3) & & $3.00(\mathrm{~m})$ & \\
\hline 3 & $1.97(\mathrm{~m}) 1.72(\mathrm{~m})$ & 23.3 & $1.95(\mathrm{~m}) 1.68(\mathrm{~m})$ & 16.4 & $1.78(\mathrm{~m}) 1.69(\mathrm{~m})$ & 17.6 \\
\hline 4 & $3.89(\mathrm{dd}, 6.6,3.0)$ & 68.9 & $1.89(\mathrm{~m})$ & 30.9 & $1.99(\mathrm{~m})$ & 21.3 \\
\hline $4 a$ & - & 77.4 & - & 76.3 & $3.02(\mathrm{~m})$ & 39.1 \\
\hline 5 & - & 142.4 & - & 144.8 & - & 140.5 \\
\hline 6 & 7.06 (br d, 6.0) & 135.5 & 7.02 (br d, 6.0) & 134.5 & 7.17 (br d, 5.8) & 137.2 \\
\hline 7 & 6.02 (br d, 6.0) & 126.6 & 6.00 (br d, 6.0) & 126.7 & 6.15 (br dt, 5.9) & 129.3 \\
\hline $7 a$ & 4.36 (br s) & 67.0 & $4.13(\mathrm{br} \mathrm{s})$ & 66.9 & $4.25(\mathrm{dd}, 6.5,2.3)$ & 59.4 \\
\hline 8 & $6.15(\mathrm{~d}, 11.2)$ & 125.2 & $6.10(\mathrm{~d}, 11.2)$ & 123.0 & $6.04(d, 11.1)$ & 123.4 \\
\hline 9 & $6.49(\mathrm{ddq}, 14,11.2,1.5)$ & 127.5 & $6.47(\mathrm{ddq}, 14.0,11.2,1.6)$ & 127.4 & $6.52(\mathrm{ddq}, 14,11.1,1.6)$ & 127.6 \\
\hline 10 & $5.91(\mathrm{dq}, 14,6.7)$ & 132.1 & $5.88(\mathrm{dq}, 14.0,6.8)$ & 131.5 & $5.83(\mathrm{dq}, 14,6.8)$ & 130.2 \\
\hline 11 & $1.85(\mathrm{br} \mathrm{d}, 6.7)$ & 17.1 & $1.84(\mathrm{dd}, 6.9,1)$ & 17.1 & $1.83(\mathrm{brd}, 6.9)$ & 16.9 \\
\hline
\end{tabular}

signal resolution (Supplementary Figure S22), but $\mathrm{CD}_{3} \mathrm{OD}$ was selected for elucidation in order to facilitate comparison with argimycin PIV, argimycin PV and argimycin PVI (Supplementary Figure S23). This comparison clearly shows that argimycin PIII is not structurally similar to the other three fused bicyclic argimycins $\mathrm{P}$. In this case, dereplication based on molecular formula and NMR signals (DNP NMR features) provided a candidate, the previously described alkaloid nigrifactin (UV/vis max at $350 \mathrm{~nm}$ ), which indeed is biosynthetically related to the argimycins PIV-PVI. Further analysis including bidimensional NMR spectra permitted the elucidation and signal assignment described in Table 7. All-trans stereochemistry of the double bonds was confirmed by analysis of coupling constants.

Argimycin PIX possesses a molecular formula of $\mathrm{C}_{12} \mathrm{H}_{21} \mathrm{~N}$, according to the base peak $\mathrm{m} / z[\mathrm{M}+\mathrm{H}]^{+}$observed at 180.1753 (calcd. for $\mathrm{C}_{12} \mathrm{H}_{22} \mathrm{~N}^{+}=180.1747$ ). Searching this molecular formula in the DNP retrieved just one hit, 2-octylpyrrole which was not compatible with the NMR spectrum observed for argimycin PIX. The molecular formula contains two degrees of unsaturation less than nigrifactin $\left(\mathrm{C}_{12} \mathrm{H}_{17} \mathrm{~N}\right)$, which agrees with a structure similar to that of nigrifactin with two double bonds less, reducing the conjugation level in agreement with the observed UV maximum at $225 \mathrm{~nm}$ (compared to the $352 \mathrm{~nm}$ for nigrifactin). The ${ }^{1} \mathrm{H}-\mathrm{NMR}$ (Supplementary Figure S24) and HSQC (Supplementary Figure S25) spectra showed four olefinic methine groups, one aliphatic N-bound methine, one methyl doublet very similar to that of nigrifactin and six aliphatic methylene groups (one of them bound to N). All these features were in agreement with the preliminary hypothesis of a partially reduced nigrifactin structure. Further analysis of the whole set of 2D NMR spectra (including COSY and HMBC) allowed the elucidation of the compound structure. The configuration of double bonds was established by analysis of the coupling constants, permitting the elucidation and signal assignment described in Table 7.

Cytotoxic activity of argimycins $\mathrm{P}$ was evaluated against a panel of 59 tumor cell lines, using $10 \mu \mathrm{M}$ concentrations. None of them showed cytotoxic activity (data not shown). In

TABLE 7 | NMR data for argimycin PIII (nigrifactin) and argimycin PIX $\left({ }^{1} \mathrm{H}, 500 \mathrm{MHz} ;{ }^{13} \mathrm{C}, 150 \mathrm{MHz}\right.$, in $\left.\mathrm{CD}_{3} \mathrm{OD}\right)$.

\begin{tabular}{|c|c|c|c|c|}
\hline \multirow[b]{2}{*}{ Carbon } & \multicolumn{2}{|c|}{ Argimycin PIII (nigrifactin) } & \multicolumn{2}{|c|}{ Argimycin PIX } \\
\hline & $\delta_{\mathrm{H}}$ (mult, J, Hz) & $\delta_{c}(p p m)$ & $\delta_{\mathrm{H}}($ mult, $J, \mathrm{~Hz})$ & $\delta_{C}(p p m)$ \\
\hline 3 & $1.94(\mathrm{~m})$ & 19.5 & $1.85(\mathrm{~m}) 1.65(\mathrm{~m})$ & 22.1 \\
\hline 4 & $1.91(\mathrm{~m})$ & 16.4 & 1.90 (m) 1.56 (qt, 12.9, 2.8) & 21.6 \\
\hline 5 & $3.02(\mathrm{~m})$ & 24.4 & $2.05(\mathrm{br} \mathrm{dt}, 14.0) 1.40(\mathrm{br} \mathrm{dd}, 13.0$ 2.9) & 28.0 \\
\hline 8 & $7.58(\mathrm{dd}, 15,11)$ & 149.5 & $2.20(\mathrm{~m})$ & 27.3 \\
\hline 9 & $6.45(d d, 13,11)$ & 127.7 & $5.52(\mathrm{ddd}, 14.0,7.0)$ & 128.4 \\
\hline 10 & $6.91(\mathrm{dd}, 14,11)$ & 146.6 & $6.08(\mathrm{dd}$, ca 14.0, 12.0) & 131.7 \\
\hline 11 & $6.34(\mathrm{dd}, 14,11)$ & 131.3 & $6.04(\mathrm{dd}$, ca 14.0, 12.0) & 131.1 \\
\hline 12 & $6.20(\mathrm{~m})$ & 139.0 & $5.64(\mathrm{dq}, 14.0,6.8)$ & 127.3 \\
\hline
\end{tabular}



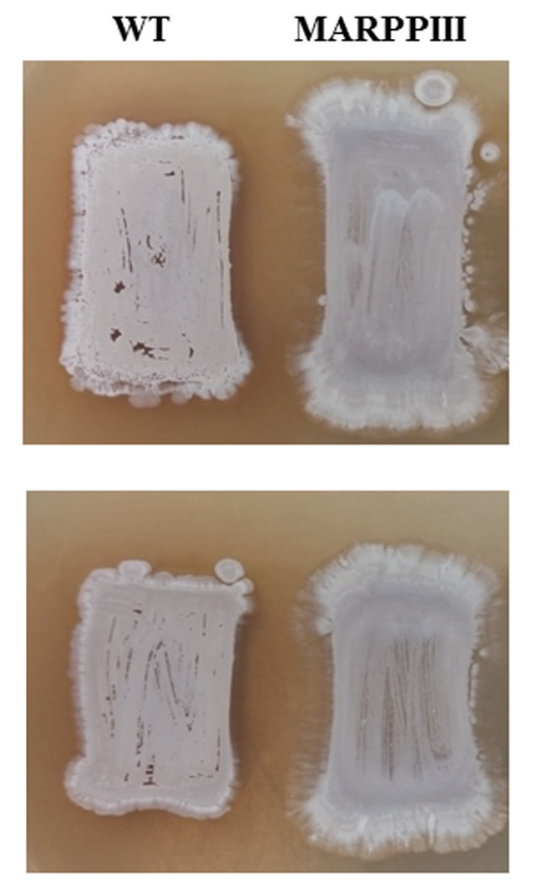

\section{MARPPIII + +pEM4ATCPKS}

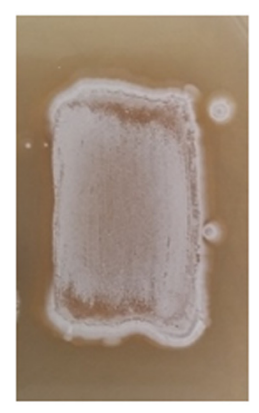

\section{MARPRII DARPO-HII}

FIGURE 4 | Morphology of S. argillaceus strains: argimycins P producers (wild type, WT; MARPRII); non-producer mutants (MARPPIII; DARPO-HII); and complemented mutant (MARPPIII + pEM4TCPKS).

antibiotic activity tests nigrifactin (argimycin PIII), argimycins PI and PII, and argimycin PVI showed weak antibiotic activity against Micrococcus luteus (data not shown). On the other hand, production of argimycins $\mathrm{P}$ exerts some effect on S. argillaceus development. Growth on agar plates of argimycins $\mathrm{P}$ producer and non-producer strains revealed that non-producer mutants $S$. argillaceus MARPPIII and $S$. argillaceus DARPO-HII grow and sporulate better than producer strains (wild type and the overproducer strain S. argillaceus MARPRII). Moreover, after complementing S. argillaceus MARPPIII (S. argillaceus MARPPIII-pEM4ATCPKS) this phenotype was reversed (Figure 4). This suggests that argimycins P play some role in colony development in S. argillaceus.

\section{Limits of arp Biosynthesis Gene Cluster}

Since cluster 18 was shown to encode argimycins P, this cluster was renamed as cluster arp. Limits of the arp cluster were established by comparing genes (and their gene products) located at each end of the cluster with others in data-bases, together with inactivating single genes and/or deleting set of genes located at both ends (Table 1, Figure 1; Supplementary Figures S26-S32), followed by analysis of argimycins $\mathrm{P}$ production in mutant strains (Supplementary Figure S33).

At the left end of the cluster, a gene coding for an unknown protein (orf3) and several others coding for regulatory proteins (orf1, orf2 and arpRI) were located. orf1 to orf3 were homologous to genes in other Streptomyces that were not involved in the biosynthesis of secondary metabolites, either showing the same (Streptomyces sp. NRRL WC-3719) or slightly different genetic organization (as in Streptomyces sp. 769, Streptomyces sp. MspMP-M5 and S. natalensis ATCC 27448). This suggested that these genes were not involved in argimycins $\mathrm{P}$ biosynthesis. To confirm this, orf3 was inactivated by gene replacement. Using pHZMutorf3, the wild type copy of orf 3 was replaced by an apramycin resistance cassette, generating mutant MORF3. Analysis of cultures of mutant MORF3 revealed that still produces argimycins $\mathrm{P}$, confirming that orf3 was not necessary for argimycin $\mathrm{P}$ biosynthesis. To establish the left boundary of the cluster, inactivation of $\operatorname{arpRI}$ was carried out. Using pHZMutSARP mutant MARPRI was generated by gene replacement. No argimycins $\mathrm{P}$ were detected in cultures of MARPRI, proving the involvement of $\operatorname{arpRI}$ in argimycins $\mathrm{P}$ biosynthesis. Therefore, the left boundary of arp cluster was established as $\operatorname{arpRI}$ (Figure 1).

On the right end of the cluster there were genes coding for enzymes and regulatory proteins that could be involved in argimycins $\mathrm{P}$ biosynthesis. To establish the right end of the arp cluster, deletion and inactivation of specific genes were carried out in a sequential way, starting from the far $3^{\prime}$-end of the cluster. First, orf19 to orf 21 were deleted and replaced by an apramycin resistance cassette using pHZdel2. Since the resultant mutant DORF19-21 still produced argimycins $\mathrm{P}$, orf11 to orf16 were deleted next. This DNA region included orf11, which codes for a putative AMP-dependent syntethase and ligase that could be involved in activating the cysteine residue that is present in argimycins PI and PII. Using pHZDel13 mutant DORF11-16 was generated and still produced argimycins $\mathrm{P}$, including argimycins PI and PII, indicating that this region is not required for argimycins $P$ biosynthesis and specifically, that orf 11 is not involved in activating the cysteine residue for the biosynthesis of argimycin PI and PII. orf9 codes for an $\mathrm{N}$-acetyl-transferase that was envisioned to be involved in transferring the acetyl group to the cysteine residue in argimycins PI and PII. Therefore, orf9 was inactivated next. Using plasmid pHZMutNAcTr, mutant MORF9 was generated and still produced argimycins $\mathrm{P}$, including PI and PII. This indicated that the orf9 gene product was not the acetyl-transferase involved in the biosynthesis of these argimycins P. Deletion of orf5 to orf7 (includes a transcriptional repressor and an oxidase) and inactivation of orf4 (coding for a reductase) were carried out next. Using plasmids pHZDel1820 and pHZMutorf17, mutants DORF5-7 and MORF4 were generated by gene replacement. UPLC analysis of culture extracts from these mutants showed that in both cases argimycins $\mathrm{P}$ were still produced. All these results and the mentioned above with MARPRII mutant, indicated that orf4 to $\operatorname{orf} 23$ were not necessary for argimycins $\mathrm{P}$ biosynthesis, and established the right end of the cluster at $\operatorname{arpRII}$ (Figure 1). In addition, these results showed that neither orf9 nor orf 11 were required for the formation of NAC moiety of argimycins PI and PII. 


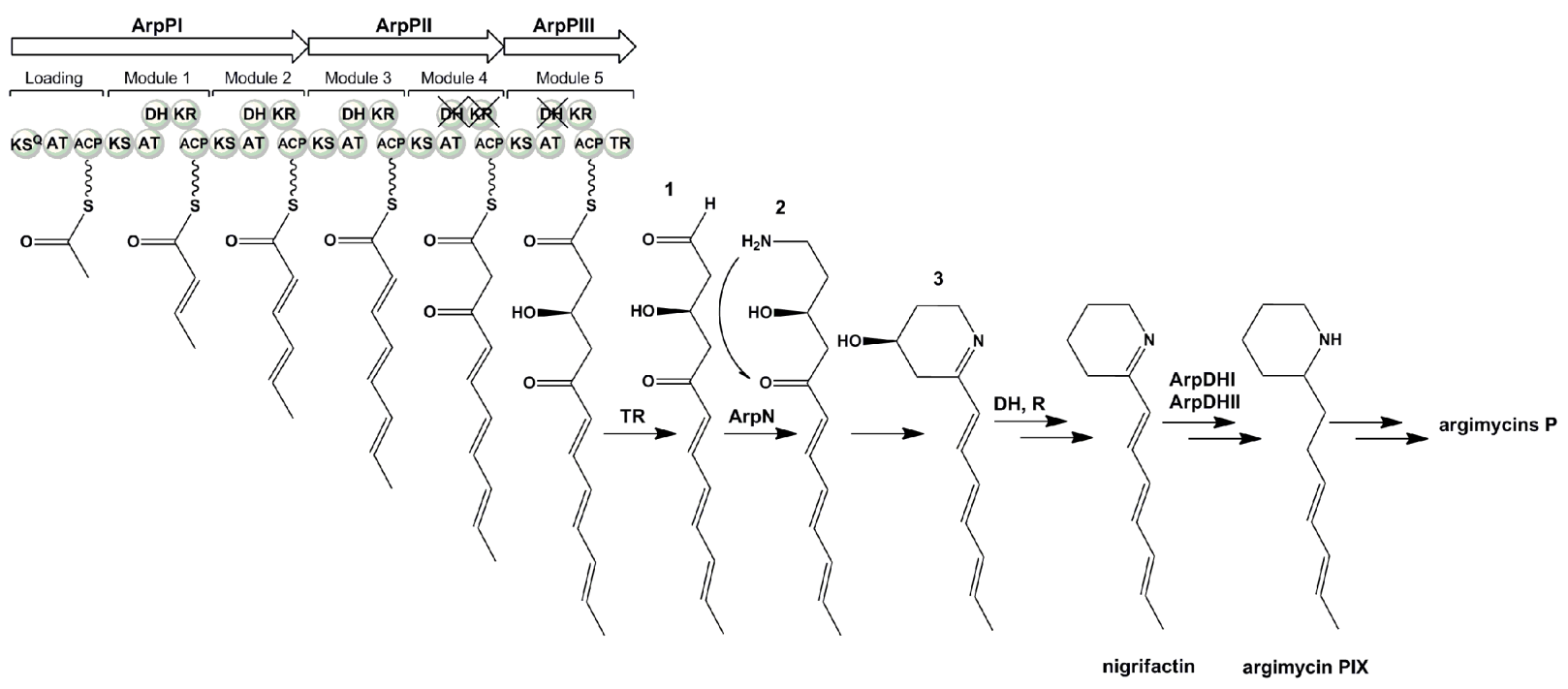

FIGURE 5 | Proposed biosynthesis pathway for argimycins P.

\section{Analysis of Argimycin P Biosynthesis Gene Cluster and Proposed Biosynthesis Pathway}

The arp cluster spanned $45.282 \mathrm{~kb}$ and includes fourteen genes: two coding for regulatory proteins ( $\operatorname{arpRI}$ and $\operatorname{arpRII),~eleven~for~}$ structural proteins (arpPI, $\operatorname{arpPII}, \operatorname{arpPIII}, \operatorname{arpT}, \operatorname{arpN}, \operatorname{arpDHI}$, $\operatorname{arpDHII}, \operatorname{arpHI}, \operatorname{arpHII}, \operatorname{arpO}$, and $\operatorname{arpK})$, and one for a hypothetical protein $(\operatorname{arpX})$ (Figure 1; Table 3).

The ArpP type I modular PKS would synthesize a 12-carbon PK backbone (Figure 5). It is constituted by three subunits: ArpPI containing the loading domain (LD) and extension modules 1 (M1) and 2 (M2); ArpPII with the third and fourth extension modules (M3 and M4); and ArpPIII with the fifth extension module (M5) and a thioester reductase domain (TR) (Figure 5). All five extension modules and the LD contain a $\beta$-ketoacyl synthase (KS), an acyl carrier protein (ACP) and acyltransferase (AT) domain. KS domains will be responsible for the decarboxylative Claisen condensations of six acyl-CoA units to form the PK chain. The KS domains from M1 to M5 contain the catalytic triad $\mathrm{CHH}$ (Xu et al., 2013). In the $\mathrm{LD}$, Gln is replacing Cys within the conserved amino acid region AQSSS, indicating that the starter unit in the polyketide biosynthesis would be malonyl-CoA (Bisang et al., 1999). All ArpP ACPs contain the conserved Ser residue to which the phosphopantetheine arm is linked (Donadio and Katz, 1992). The ArpP AT domains contain the conserved amino acid region GHSxG around the catalytic Ser residue, and are predicted to accept malonyl-CoA as substrate since they carry signature motifs associated with malonyl-CoA substrate specificity (Haydock et al., 1995; Reeves et al., 2001; Yadav et al., 2003): presence of a branched hydrophobic residue (Ile) beyond the catalytic Ser; and a HAFH motif that includes the catalytic His. All five extender modules in ArpP PKS contain a KR and a DH domain. All ArpP KR domains contain the NADP(H)-binding motif and the catalytic triad KSY (Reid et al., 2003). KRs are usually of B1 type when they work together with processing enzymes like DHs (Keatinge-Clay, 2007). Based on sequence fingerprints in the LDD loop, catalytic region and Lid (Caffrey, 2003; KeatingeClay, 2007), all ArpP KRs except KR4, could be classified into the B1 type. Interestingly, in KR4 the conserved LDD motif is not preserved: there is an Asn residue instead of the strictly conserved Asp. Its absence could indicate that this KR is of A-type. However, A-type KRs usually possess a Trp residue $\mathrm{N}$-terminal to the catalytic Tyr that is absent in KR4 (Caffrey, 2003; KeatingeClay, 2007). This fact could indicate a malfunctioning of KR4 that could lead to a keto group at C8 in the nascent polyketide chain (Figure 5). All ArpP modules contain a DH domain. DH1, $\mathrm{DH} 2$ and DH3 show the four hallmark DH motifs, including those around the catalytic residues His (HxxxGxxxxP) and Asp (DxxxQ/H) (Keatinge-Clay, 2008). However, in DH4 and DH5 two of these motifs are lacking, which indicates that DH4 and DH5 are inactive. Products of B-type KRs are dehydrated to trans-double-bonds by the corresponding DH (Xu et al., 2013). Accordingly, the polyene side chain of nigrifactin (argimycin PIII), a putative early shunt product in argimycins $\mathrm{P}$ biosynthesis, which would result from the activity of ArpP and ArpN (see below), shows three trans-double-bonds. Typically, the release of the full length polyketide chain is catalyzed by a thioesterase domain (TE) located at the C-terminal of the last module. However, in the ArpP PKS there is a TR domain instead that would be responsible for the $\mathrm{NAD}(\mathrm{P}) \mathrm{H}$-dependent reductive release of the acyl thioester attached to the adjacent ACP domain (Du and Lou, 2010) to yield the putative aldehyde product $\mathbf{1}$ (Figure 5). This TR domain shows the consensus motifs usually found in this type of domains, both in NRPS and PKS (Konz and Marahiel, 1999).

ArpT shows similarity to type II thioesterases such as TamB (ADC79640.1; 47\% identical amino acids) and TrdB (ADY38534.1; 47\% identical amino acids from tirandamycin 


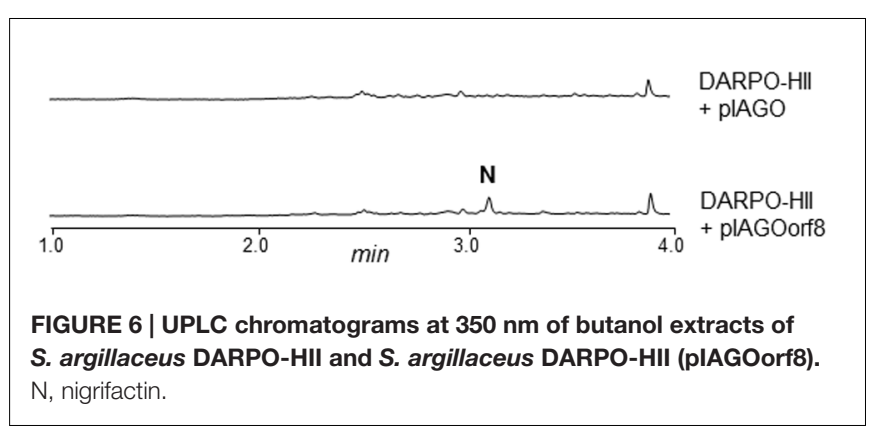

gene clusters in Streptomyces sp. 307-9 (Carlson et al., 2010) and Streptomyces sp. SCSIO1666 (Mo et al., 2011), respectively; and ScoT (NP_630685.1; 53\% identical amino acids) from the coelimycin P1 gene cluster in S. coelicolor M145 (Pawlik et al., 2007; Gómez-Escribano et al., 2012). These proteins are editing proteins that eliminate aberrant polyketide growing chains from PKS, thus allowing its normal correct function (Heathcote et al., 2001; Mo et al., 2011).

ArpN shows similarity to class III aminotransferases such as $\mathrm{CpkG}$ (67\% identical amino acids) that is involved in the biosynthesis of coelimycin P1 in S. coelicolor (Pawlik et al., 2007; Gómez-Escribano et al., 2012). These pyridoxal phosphate (PLP)-dependent enzymes can catalyze the transfer of an amino group from an amino donor to an aldehyde group. Accordingly, ArpN is proposed to catalyze the amination of compound $\mathbf{1}$ (Figure 5). The resultant compound 2 could spontaneously cyclize or could suffer other modifications before ring formation. For example, in the biosynthesis of coelimycin P1 it has been proposed that the transamination step is followed by several epoxidations and oxidation before cyclization of the PK chain. To understand the formation of the piperidine ring during the biosynthesis of argimycins $\mathrm{P}, \operatorname{arpN}$ was inactivated using pHZMutAT (Table 1; Supplementary Figure S34). The resultant mutant $S$. argillaceus MARPN neither produced any argimycin P nor accumulated a new compound, which indicated that ArpN was involved in the biosynthesis of argimycins $\mathrm{P}$ and suggested its participation at an early step (Supplementary Figure S35). Then, a second mutant was generated by deleting arpO to arpHII genes, using pHZDel59b (Table 1; Supplementary Figure S36). As expected, the resultant mutant S. argillaceus DARPOHII didn't produce any argimycin $\mathrm{P}$ (Figure 6). When $\operatorname{arpN}$ was expressed in this mutant, the resultant strain $S$. argillaceus DARPO-HII pIAGOorf8 produced nigrifactin (Figure 6). These results indicate that biosynthesis of nigrifactin only requires the action of ArpP PKS and aminotransferase ArpN, and suggests that compound 2 suffers a spontaneous cyclization to generate compound 3. Dehydration and reduction of this compound would result in the formation of nigrifactin (Figure 5). Moreover, these results also indicate that the other structural genes in the cluster ( $\operatorname{arpDHI}, \operatorname{arpDHII}, \operatorname{arpHI}, \operatorname{arpHII}, \operatorname{arpK}$, and $\operatorname{arpO})$ must be involved in later steps in the biosynthesis pathway leading to the formation of argimycins PI/PII, PIV, PV, PVI and PIX.

ArpDHI and ArpDHII show high similarity to several dehydrogenases. ArpDHI was similar to hypothetical acylCoA dehydrogenases. It contains the Acyl-CoA dehydrogenase,
C-terminal domain (pfam080028). These proteins catalyze FAD-dependent dehydrogenation steps. It also contains the conserved protein domain $\mathrm{NcnH}(\mathrm{cd} 01159)$. This is a hydroxylase involved in the biosynthesis of polyketide naphthocyclinone that hydroxylates several substrates such as aloesaponarin II and SEK26 (Brünker et al., 2001). We propose ArpDHI could hydroxylate the piperidine ring and/or reduce the $\mathrm{C} 7-\mathrm{C} 8$ double bond of the polyene chain during the biosynthesis of argimycins P. The identification of argimycin PIX that lacks the C7-C8 double bond in the polyene chain (Figure 3) supports the existence of a dehydrogenase acting at the polyene chain.

ArpDHII is similar to putative 6-phosphogluconate dehydrogenases. It belongs to the Rossmann fold superfamily, and contains the NAD_binding_2 domain of 6-phosphogluconate dehydrogenases (pfam03446) and the NAD(P) binding domain of Shikimate dehydrogenase (cd01065). In addition, a Blastp search with ArpDHII using the Protein Data Bank proteins (PDB) gave significant alignments with several imine reductases, such as Q1EAE0 (acc. number 3ZGY_A) from Streptomyces kanamyceticus (Rodríguez-Mata et al., 2013) and AoIRED (acc. number 5A9S_B) from Amycolatopsis orientalis (Aleku et al., 2016). We suggest that ArpDHII could be an imine reductase that catalyzes the reduction of the imine group of argimycins $\mathrm{P}$.

ArpHI and ArpHII belong to the NTF2_like superfamily, and contain a SnoaL-like domain (pfam12680 and pfam13474, respectively). SnoaL is a polyketide cyclase which catalyzes the last cyclization step during nogalamycin biosynthesis (Sultana et al., 2004). ArpHI shows similarity to hypothetical proteins, while ArpHII was similar to several putative hydrolases. In addition, ArpHI and ArpHII were similar to StzF and StzE, respectively. These two proteins have recently been proposed to act as cyclases during streptazone E biosynthesis (Ohno et al., 2015). We propose ArpHI and ArpHII to be involved in the formation of the five-membered ring present in some argimycins $\mathrm{P}$.

ArpO shows high similarity to several putative oxidases. It contains a NAD(P)-binding Rossmann domain (pfam13450) and a putative FAD-binding dehydrogenase domain (PRK12834). Also, it contains domains that belong to the conserved protein domain families desat_CrtD (TIGR02733) and CrtI_fam (TIGR02734). These enzymes catalyze desaturation/dehydrogenation reactions. According to that, ArpO could carry out dehydrogenation/oxidation reactions during biosynthesis of argimycins $\mathrm{P}$.

ArpK shows high similarity to flavin reductases, and contains flavin reductase like domains (smart00903 and pfam01613). ArpK could be involved in regenerating flavin nucleotides that could be used by putative dehydrogenases ArpDHI and ArpO.

The arp gene cluster contains two regulatory genes located at the boundaries of the cluster. arpRI codes for a SARPlike regulatory protein (Wietzorrek and Bibb, 1997). At its N-terminus contains a Trans_reg_C (Pfam00486), followed by a BTAD (Bacterial Transcriptional Activation Domain) (cd158319) domain; and at its C-terminus, the ATP-binding domain AAA_16 (Pfam13191). ArpRI behaves as a transcriptional activator. Its inactivation completely blocked argimycins $\mathrm{P}$ production, as it 


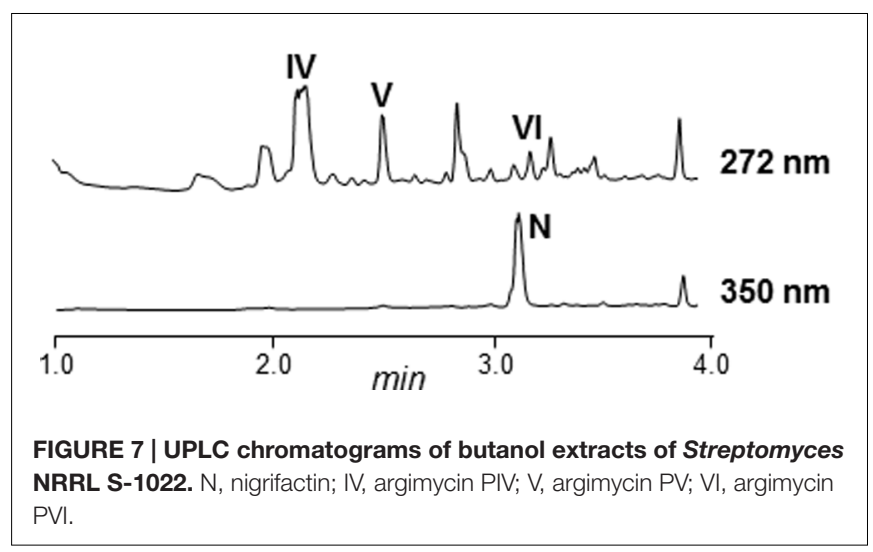

was shown in S. argillaceus MARPRI (see above). arpRII codes for a transcriptional regulator belonging to the TetR family (Ramos et al., 2005). It contains the TetR domain (pfam00440). As shown above, ArpRII behaves as a transcriptional repressor, since its inactivation led to an increase in argimycins $\mathrm{P}$ production (S. argillaceus MARPRII). In addition, the arp cluster contains a gene $(\operatorname{arp} X)$, whose product shows high similarity to hypothetical proteins from different Streptomyces. At this moment, no role can be assigned to this gene product in argimycins $\mathrm{P}$ biosynthesis.

Most of the arp gene products show high similarity to proteins from an incomplete and uncharacterized PKS gene cluster in Streptomyces sp. NRRL S-1022 (Table 3; Supplementary Figure S37). Specifically, there was high similarity and synteny between upstream genes of the PKS region, and also with the $\operatorname{arpT}$ gene product. Upstream of $\operatorname{arpRI}$ and downstream of $\operatorname{arp} T$, the similarity is lost, that is in Streptomyces sp. NRRL S-1022 there are no homologous genes to $\operatorname{arpX}$ and $\operatorname{arpRII}$. To determine if this strain also produces argimycins $P$, the strain was obtained from the NRRL culture collection and cultivated. Butanol extracts of cultures of this strain showed production of argimycin PIII (nigrifactin), argimycin PIV, argimycin PV and argimycin PVI (Figure 7). This confirmed that genes arpRI to $\operatorname{arp} T$ are sufficient to synthesize these argimycins P. However, no argimycin PI and PII was detected (data not shown), reinforcing the hypothesis that enzymes required for the formation and incorporation of NAC moiety to these compounds are encoded by genes outside the arp cluster.

\section{DISCUSSION}

The first genome sequences obtained from Streptomyces revealed that these microorganisms had greater potential to produce secondary metabolites than expected (Bentley et al., 2002; Ikeda et al., 2003). The improvement and development of sequencing technologies and bioinformatic tools has allowed the use of genome mining as a new and effective approach to discover new metabolites produced by microorganism, by activating and/or increasing production of unknown compounds encoded by cryptic biosynthesis gene clusters (Olano et al., 2014; Rutledge and Challis, 2015; Ochi, 2016). Genome mining applied to the antitumor mithramycin producer S. argillaceus has allowed the identification of 31 gene clusters for the biosynthesis of secondary metabolites. In addition to the mithramycin gene cluster, which has been previously characterized (Lombó et al., 2006), the metabolic products of 11 gene clusters could be predicted. Cluster 18 (renamed as arp cluster) was related to the coelimycin P1 and the recently reported streptazone E gene cluster (Gómez-Escribano et al., 2012; Ohno et al., 2015), and was predicted to direct the biosynthesis of a PK derived from the condensation of six malonyl-CoA units. Identification of compounds encoded by this cluster was carried out by combining several strategies: (i) inactivation of the type I PKS gene arpPIII to block production of compounds; (ii) inactivation of the putative TetR-transcriptional repressor arpRII to increase production of compounds; (iii) cultivation of wild type and mutant strains in different production media, to increase production and identification of compounds; and (iv) use of strains with increased intracellular amounts of malonyl-CoA, to favor the biosynthesis of the malonyl-CoA derived PK chain. Using this combined strategy seven compounds were identified, one of them, nigrifactin, previously identified in Streptomyces FFD101(Terashima et al., 1969). The remaining newly discovered compounds were named argimycins P. Nigrifactin and argimycin PIX are simple piperidine alkaloids consisting of a piperidine ring with a polyene chain attached. They differ in the nitrogen atom that is reduced in argimycin IX, and in the existence of a C7-C8 double bond in the polyene chain in nigrifactin absent in argimycin PIX. Argimycin PIV, argimycin PV and argimycin PVI differ in their hydroxylation pattern, and contain a piperidine ring fused to a five-membered ring and a shorter polyene side chain. They are structurally related to pyrindicin (Onda et al., 1973) and streptazones E and F (Liu et al., 2013), and to other alkaloids with shorter side chains such as abikoviromycin (latumcidin) (Umezawa et al., 1951; Sakagami et al., 1958). Argimycins PI and PII are isomers, and unlike argimycins PIV-PVI contain a pyridine ring, and additionally, they contain a NAC residue attached to the polyene chain. For some of the piperidine alkaloid compounds structurally related to argimycins $\mathrm{P}$ antimicrobial, cytotoxic and antiviral activities has been reported (Umezawa et al., 1951; Puder et al., 2001). In some of these compounds, bioactivity has been related to the presence of double bonds, an epoxy group, or an imine group in the piperidine ring, among others (Hegde et al., 1994; Puder et al., 2000; Maruyama et al., 2003; Liu et al., 2013). In addition, some of these and related compounds have been shown to exert other activities such as decreasing blood pressure, inhibiting biosynthesis of cholesterol or having analgesic properties (Terashima et al., 1970; Grabley et al., 1991). Some argimycins $\mathrm{P}$ also showed weak antibiotic but no cytotoxic activity, being argimycin PIII (nigrifactin) the most active one. If they display other activities is unknown at this time and remains to be discovered. On the other hand, argimycins $\mathrm{P}$ seem to play a role in growth and colony development in S. argillaceus: argimycins $\mathrm{P}$ non-producer mutants show better growth and sporulation than producer strains. Therefore, expression of the arp cluster and/or production of the encoded argimycins $\mathrm{P}$ seem to reduce/decrease colony growth and development in 
S. argillaceus. Further studies will be required to understand the role of these genes and compounds on these processes.

The boundaries of the arp biosynthesis gene cluster have been determined by inactivating/deleting genes at both ends of the cluster. It contains 14 genes, including two coding for regulatory proteins, 11 for structural proteins and one for a hypothetical protein. The arp cluster shows high similarity to a partial and uncharacterized cluster from Streptomyces NRRL S-1022, and to the recently published stz gene cluster from Streptomyces sp. MSC090213JE08 (Ohno et al., 2015). The genes $\operatorname{arpX}$ and $\operatorname{arpRII}$ are absent in those strains. The hypothetical role of $\operatorname{arpX}$ is unclear. In the case of $\operatorname{arpRII}$, we have shown that codes for a putative TetR-like repressor of argimycins $\mathrm{P}$ biosynthesis, since its inactivation greatly increases argimycins $\mathrm{P}$ production. In the case of Streptomyces sp. MSC090213JE08, there is no evidence of argimycin $\mathrm{P}$ production, although nigrifactin has been proposed as a biosynthesis intermediate (Ohno et al., 2015). However, in this manuscript we have shown that Streptomyces NRRL S-1022 actually produces most argimycins $\mathrm{P}$, which indicates that those homologous genes between $S$. argillaceus and S1022 strains are sufficient for the biosynthesis of the piperidine ring containing argimycin $\mathrm{P}$ compounds. The pyridine ring containing compounds argimycin PI and argimycin PII haven't been identified in cultures of S-1022 strain, which might indicate that enzymes for generating these compounds are encoded by genes located outside of the arp cluster, and are strain specific.

Based on the structure of argimycins $\mathrm{P}$ and on the bioinformatic analysis of the arp cluster, a pathway for the early steps in argimycins $\mathrm{P}$ biosynthesis is proposed (Figure 5). This would start by the condensation of six malonyl-CoA units by PKS ArpP. According to the presence of KR and DH domains in modules 1 to 3 of ArpP, the first three elongation steps would be followed by the ketoreduction and dehydration of the resulting $\beta$-keto groups to render trans-double bonds at the corresponding sites. Considering that the KR domain of module 4 as well as the $\mathrm{DH}$ domains of modules 4 and 5 are inactive, the resulting $\mathrm{PK}$ chain would contain a $\beta$-keto group at C8 and a hydroxyl group at C10. Since module 5 contains a TR domain, this PK chain would be released to render the putative aldehyde $\mathbf{1}$. This compound would be the substrate for aminotransferase ArpN, rendering the hypothetical product 2 that can spontaneously cyclize to form the piperidine ring. In this report, we have shown that formation of this ring in $S$. argillaceus only requires ArpP and ArpN. We propose that the reaction product of these enzymes would be compound 3 (Figure 5). Piperidine compounds with a hydroxyl group at $\mathrm{C} 4$ but with a shorter side chain have been identified in cultures of piperidineproducing organisms (Grabley et al., 1991; Groenhagen et al., 2014). Spontaneous dehydration and reduction of compound 3 would render nigrifactin (Figure 5). Its reduction at the C7-C8 double bond and at the imine group by ArpDHI and ArpDHII, would result in the formation of argimycin PIX. Late biosynthetic steps would involve formation of the fused five-membered ring and incorporation of NAC adduct, among others. Candidates for the cyclization reaction could be ArpHI/ArpHII, which contain a domain present in the SnoaL cyclase from the nogalamycin pathway (Sultana et al., 2004), and are similar to two putative cyclases from the streptazone E pathway (Ohno et al., 2015). Within the arp cluster there are no candidate genes for formation and transfer of NAC. Downstream of the cluster, there are two genes (orf11 and orf9) that were initially proposed to be involved in this process. However, as mentioned above, inactivation of these genes did not abolish argimycins PI/PII production. In coelimycin P1 biosynthesis pathway, Gómez-Escribano et al. (2012) have hypothesized that incorporation of the NAC adduct would take place by ring opening of bis-epoxide of a biosynthesis intermediate via nucleophilic attack of the NAC thiol group. In the case of argimycins $\mathrm{P}$ biosynthesis pathway, it is possible that ArpO, which is similar to different oxidases, could be involved in oxidizing the side chain, being the resultant product substrate for the incorporation of NAC. Future studies would be required to clarify biosynthetic steps downstream of the formation of piperidine ring.

\section{CONCLUSION}

By genome mining of $S$. argillaceus we have identified the type I cryptic arp gene cluster and the encoded argimycins $\mathrm{P}$ family of new compounds, which in addition to antibiotic activity, they seem to play a role in colony growth and development of this strain.

\section{Notes in Proof}

Very recently, it has been shown that the TR domains of the PKS and the $\omega$-aminotransferases (which are similar to ArpP-TR and ArpN respectively) involved in the biosynthesis of polyketide alkaloids coelimycin P1 and cyclizidine, are responsible for the release of the polyketide chain as an aldehyde and its subsequent transamination (Awodi et al., 2016; Peng et al., 2016). On the other hand, Peng et al. (2016) have shown that 3-hydroxyl-6methyl-piperidine (an analog of compound 3 ) is the substrate for imine reduction, and it is unstable being readily transformed in a dehydrated product.

\section{AUTHOR CONTRIBUTIONS}

CM, JS, and FM conceived and designed the project; SY, DZ, and JC conducted experiments; $\mathrm{AB}$ carried out compound purifications; SY, BM, CO, and CM performed sequence in silico analysis; CM wrote the manuscript, and FM and JS contributed to preparing the final version of the paper. All authors read and approved the final manuscript.

\section{ACKNOWLEDGMENTS}

This work was supported by grants to CM from the Spanish Ministry of Economy and Competitiveness, MINECO (Grants BIO2011-25398, BIO2014-56752-R and PIM2010EEI-00752) and “Apoyo a grupos de excelencia," Principado de Asturias-FEDER (FC-15-GRUPIN14-014). EntreChem SL acknowledges funding to the ERA-IB program and MINECO (PIM2010EEI-00752). SY and DZ were recipient of predoctoral fellowships from 
MINECO. We thank Fundación Bancaria Cajastur for financial support to CO, and we also thank Dr. Fernando Reyes from Fundación Medina, and Dr. Javier González-Sabín and Dr. Nicolás Ríos-Lombardía from Entrechem S.L. for technical support in structural elucidation compounds.

\section{REFERENCES}

Aguirrezabalaga, I., Olano, C., Allende, N., Rodriguez, L., Braña, A. F., Méndez, C., et al. (2000). Identification and expression of genes involved in biosynthesis of L-oleandrose and its intermediate L-olivose in the oleandomycin producer Streptomyces antibioticus. Antimicrob. Agents. Chemother. 44, 1266-1275. doi: 10.1128/AAC.44.5.1266-1275.2000

Aleku, G. A., Man, H., France, S. P., Leipold, F., Hussain, S., Toca-Gonzalez, L., et al. (2016). Stereoselectivity and structural characterization of an imine reductase (IRED) from Amycolatopsis orientalis. ACS Catal. 6, 3880-3889. doi: 10.1021/acscatal.6b00782

Altschul, S. F., Madden, T. L., Schäffer, A. A., Zhang, J., Zhang, Z., Miller, W., et al. (1997). Gapped BLAST and PSI-BLAST: a new generation of protein database search programs. Nucleic Acids Res. 25, 3389-3402. doi: 10.1093/nar/25.17.3389

Angiuoli, S. V., Gussman, A., Klimke, W., Cochrane, G., Field, D., Garrity, G., et al. (2008). Toward an online repository of standard operating procedures (SOPs) for (meta)genomic annotation. OMICS 12, 137-141. doi: 10.1089/omi. 2008.0017

Awodi, U. R., Ronan, J. L., Masschelein, J., de los Santosa, E. L. C., and Challis, G. L. (2016). Thioester reduction and aldehyde transamination are universal steps in actinobacterial polyketide alkaloid biosynthesis. Chem. Sci. 8, 411-415. doi: 10.1039/C6SC02803A

Barka, E. A., Vatsa, P., Sanchez, L., Gaveau-Vaillant, N., Jacquard, C., Klenk, H. P., et al. (2016). Taxonomy, physiology, and natural products of Actinobacteria. Microbiol. Mol. Biol. Rev. 80, 1-43. doi: 10.1128/MMBR.00019-15

Barona-Gómez, F., Wong, U., Giannakopulos, A. E., Derrick, P. J., and Challis, G. L. (2004). Identification of a cluster of genes that directs desferrioxamine biosynthesis in Streptomyces coelicolor M145. J. Am. Chem. Soc. 126, 1628216283. doi: $10.1021 /$ ja045774k

Bauer, R. A., Wurst, J. M., and Tan, D. S. (2010). Expanding the range of 'druggable' targets with natural product-based libraries: an academic perspective. Curr. Opin. Chem. Biol. 14, 308-314. doi: 10.1016/j.cbpa.2010.02.001

Bentley, S. D., Chater, K. F., Cerdeño-Tárraga, A. M., Challis, G. L., Thomson, N. R., James, K. D., et al. (2002). Complete genome sequence of the model actinomycete Streptomyces coelicolor A3(2). Nature 417, 141-147. doi: 10.1038/ 417141a

Bisang, C., Long, P. F., Cortés, J., Westcott, J., Crosby, J., Matharu, A. L., et al. (1999). A chain initiation factor common to both modular and aromatic polyketide synthases. Nature 401, 502-505. doi: 10.1021/ja045774k

Blin, K., Medema, M. H., Kazempour, D., Fischbach, M. A., Breitling, R., Takano, E., et al. (2013). AntiSMASH 2.0-a versatile platform for genome mining of secondary metabolite producers. Nucleic Acids Res. 41, W204-W212. doi: 10. 1093/nar/gkt449

Brünker, P., Sterner, O., Bailey, J. E., and Minas, W. (2001). Heterologous expression of the naphthocyclinone hydroxylase gene from Streptomyces arenae for production of novel hybrid polyketides. Antonie Van Leeuwenhoek 79, 235-245. doi: 10.1023/A:1012037329949

Caffrey, P. (2003). Conserved amino acid residues correlating with ketoreductase stereospecificity in modular polyketide synthases. Chembiochem 4, 649-662. doi: 10.1002/cbic. 200300581

Cane, D. E., He, X., Kobayashi, S., Omura, S., and Ikeda, H. (2006). Geosmin biosynthesis in Streptomyces avermitilis. Molecular cloning, expression, and mechanistic study of the germacradienol/geosmin synthase. J. Antibiot. (Tokyo) 59, 471-479. doi: 10.1038/ja.2006.66

Carlson, J. C., Fortman, J. L., Anzai, Y., Li, S., Burr, D. A., and Sherman, D. H. (2010). Identification of the tirandamycin biosynthetic gene cluster from Streptomyces sp. 307-9. Chembiochem 11, 564-572. doi: 10.1002/cbic.20090 0658

Cragg, G. M., Newman, D. J., and Snader, K. M. (1997). Natural products in drug discovery and development. J. Nat. Prod. 60, 52-60. doi: 10.1021/np9604893

\section{SUPPLEMENTARY MATERIAL}

The Supplementary Material for this article can be found online at: http://journal.frontiersin.org/article/10.3389/fmicb. 2017.00194/full\#supplementary-material

Donadio, S., and Katz, L. (1992). Organization of the enzymatic domains in the multifunctional polyketide synthase involved in erythromycin formation in Saccharopolyspora erythraea. Gene 111, 51-60. doi: 10.1016/0378-1119(92) 90602-L

Du, L., and Lou, L. (2010). PKS and NRPS release mechanisms. Nat. Prod. Rep. 27, 255-278. doi: 10.1039/b912037h

Fernández, E., Weibbach, U., Sánchez Reillo, C., Braña, A. F., Méndez, C., Rohr, J., et al. (1998). Identification of two genes from Streptomyces argillaceus encoding two glycosyltransferases involved in the transfer of a disaccharide during the biosynthesis of the antitumor drug mithramycin. J. Bacteriol. 180, 4929-4937.

Flärdh, K., and Buttner, M. J. (2009). Streptomyces morphogenetics: dissecting differentiation in a filamentous bacterium. Nat. Rev. Microbiol. 7, 36-49. doi: 10.1038/nrmicro1968

Ghimire, G. P., Koirala, N., and Sohng, J. K. (2015). Activation of cryptic hop genes from Streptomyces peucetius ATCC 27952 involved in hopanoid biosynthesis. J. Microbiol. Biotechnol. 25, 658-661. doi: 10.4014/jmb.1408.08058

Gómez-Escribano, J. P., Song, L., Fox, D. J., Yeo, V., Bibb, M. J., and Challis, G. L. (2012). Structure and biosynthesis of the unusual polyketide alkaloid coelimycin P1, a metabolic product of the cpk gene cluster of Streptomyces coelicolor M145. Chem. Sci. 3, 2716-2720. doi: 10.1039/C2SC20410J

Grabley, S., Hammann, P., Kluge, H., Wink, J., Kricke, P., and Zeeck, A. (1991). Secondary metabolites by chemical screening. 4. Detection, isolation and biological activities of chiral synthons from Streptomyces. J. Antibiot. (Tokyo). 44, 797-800.

Groenhagen, U., Maczka, M., Dickschat, J. S., and Schulz, S. (2014). Streptopyridines, volatile pyridine alkaloids produced by Streptomyces sp. FORM5. Beilstein J. Org. Chem. 10, 1421-1432. doi: 10.3762/bjoc.10.146

Harvey, A. L., Edrada-Ebel, R., and Quinn, R. J. (2015). The re-emergence of natural products for drug discovery in the genomics era. Nat. Rev. Drug Discov. 14, 111-129. doi: 10.1038/nrd4510

Hayashi, S., Ozaki, T., Asamizu, S., Ikeda, H., Ômura, S., Oku, N., et al. (2014). Genome mining reveals a minimum gene set for the biosynthesis of 32membered macrocyclic thiopeptides lactazoles. Chem. Biol. 21, 679-688. doi: 10.1016/j.chembiol.2014.03.008

Haydock, S. F., Aparicio, J. F., Molnar, I., Schwecke, T., Khaw, L. E., Konig, A., et al. (1995). Divergent sequences motifs correlated with the substrate specificity of (methyl)malonyl-CoA:acyl carrier protein transacyclase domains in modular polyketide synthases. FEBS Lett. 374, 246-248. doi: 10.1016/0014-5793(95) 01119-Y

Healy, F. G., Eaton, K. P., Limsirichai, P., Aldrich, J. F., Plowman, A. K., and King, R. R. (2009). Characterization of gamma-butyrolactone autoregulatory signaling gene homologs in the angucyclinone polyketide WS5995B producer Streptomyces acidiscabies. J. Bacteriol. 191, 4786-4797. doi: 10.1128/JB.0043709

Heathcote, M. L., Staunton, J., and Leadlay, P. F. (2001). Role of type II thioesterases: evidence for removal of short acyl chains produced by aberrant decarboxylation of chain extender units. Chem. Biol. 8, 207-220. doi: 10.1016/ S1074-5521(01)00002-3

Hegde, V. R., Dai, P., Patel, M. G., Troyanovich, J. J., Das, P., and Puar, M. S. (1994). Isolation and identification of a novel microbial alkaloid. J. Antibiot. (Tokyo). 47, 110-112. doi: 10.7164/antibiotics.47.110

Hertweck, C. (2009). The biosynthetic logic of polyketide diversity. Angew. Chem. Int. Ed. Engl. 48, 4688-4716. doi: 10.1002/anie.200806121

Ikeda, H., Ishikawa, J., Hanamoto, A., Shinose, M., Kikuchi, H., Shiba, T., et al. (2003). Complete genome sequence and comparative analysis of the industrial microorganism Streptomyces avermitilis. Nat. Biotechnol. 21, 526-531. doi: 10. $1038 /$ nbt820

Katz, L., and Baltz, R. H. (2016). Natural product discovery: past, present, and future. J. Ind. Microbiol. Biotechnol. 43, 155-176. doi: 10.1007/s10295-0151723-5 
Keatinge-Clay, A. (2008). Crystal structure of the erythromycin polyketide synthase dehydratase. J. Mol. Biol. 384, 941-953. doi: 10.1016/j.jmb.2008.09.084

Keatinge-Clay, A. T. (2007). A tylosin ketoreductase reveals how chirality is determined in polyketides. Chem. Biol. 14, 898-908. doi: 10.1016/j.chembiol. 2007.07.009

Kieser, T., Bibb, M. J., Buttner, M. J., Chater, K. F., and Hopwood, D. A. (2000). Practical Streptomyces Genetics. Norwich: The John Innes Foundation.

Konz, D., and Marahiel, M. A. (1999). How do peptide synthetases generate structural diversity? Chem. Biol. 6, R39-R48. doi: 10.1016/S1074-5521(99) 80002-7

Krogh, A., Larsson, B., von Heijne, G., and Sonnhammer, E. L. (2001). Predicting transmembrane protein topology with a hidden Markov model: application to complete genomes. J. Mol. Biol. 305, 567-580. doi: 10.1006/jmbi.2000.4315

Liu, Q. F., Wang, J. D., Wang, X. J., Liu, C. X., Zhang, J., Pang, Y. W., et al. (2013). Two new piperidine alkaloids from Streptomyces sp. NEAU-Z4. J. Asian Nat. Prod. Res. 15, 221-224. doi: 10.1080/10286020.2012.761209

Lombó, F., Blanco, G., Fernández, E., Méndez, C., and Salas, J. A. (1996). Characterization of Streptomyces argillaceus genes encoding a polyketide synthase involved in the biosynthesis of the antitumor mithramycin. Gene 172, 87-91. doi: 10.1016/0378-1119(96)00029-7

Lombó, F., Braña, A. F., Méndez, C., and Salas, J. A. (1999). The mithramycin gene cluster of Streptomyces argillaceus contains a positive regulatory gene and two repeated DNA sequences that are located at both ends of the cluster. J. Bacteriol. $181,642-647$.

Lombó, F., Menéndez, N., Salas, J. A., and Méndez, C. (2006). The aureolic acid family of antitumor compounds: structure, mode of action, biosynthesis, and novel derivatives. Appl. Microbiol. Biotechnol. 73, 1-14. doi: 10.1007/s00253006-0511-6

Marfey, P. (1984). Determination of D-amino acids. II. Use of a bifunctional reagent, 1,5-difluoro-2,4-dinitrobenzene. Carlsberg Res. Commun. 49, 591-596. doi: $10.1007 / \mathrm{BF} 02908688$

Margulies, M., Egholm, M., Altman, W. E., Attiya, S., Bader, J. S., Bemben, L. A., et al. (2005). Genome sequencing in microfabricated high-density picolitre reactors. Nature 437, 376-380. doi: 10.1038/nature03959

Martin, N. I., Sprules, T., Carpenter, M. R., Cotter, P. D., Hill, C., Ross, R. P., et al. (2004). Structural characterization of lacticin 3147 , a two-peptide lantibiotic with synergistic activity. Biochemistry 43, 3049-3056. doi: 10.1021/bi0362065

Maruyama, H., Okamoto, S., Kubo, Y., Tsuji, G., Fujii, I., Ebizuka, Y., et al. (2003). Isolation of abikoviromycin and dihydroabikoviromycin as inhibitors of polyketide synthase involved in melanin biosynthesis by Colletotrichum lagenarium. J. Antibiot. (Tokyo). 56, 801-804. doi: 10.7164/antibiotics.56.801

Medema, M. H., Kottmann, R., Yilmaz, P., Cummings, M., Biggins, J. B., Blin, K., et al. (2015). Minimum information about a biosynthetic gene cluster. Nat. Chem. Biol. 11, 625-631. doi: 10.1038/nchembio. 1890

Menéndez, N., Nur-e-Alam, M., Fischer, C., Braña, A. F., Salas, J. A., Rohr, J., et al. (2006). Deoxysugar transfer during chromomycin A3 biosynthesis in Strepomyces griseus subsp. griseus: new derivatives with antitumor activity. Appl. Environ. Microbiol. 72, 167-177. doi: 10.1128/AEM.72.1.167-177. 2006

Mo, X., Wang, Z., Wang, B., Ma, J., Huang, H., Tian, X., et al. (2011). Cloning and characterization of the biosynthetic gene cluster of the bacterial RNA polymerase inhibitor tirandamycin from marine-derived Streptomyces sp. SCSIO1666. Biochem. Biophys. Res. Commun. 406, 341-347. doi: 10.1016/j.bbrc. 2011.02.040

Newman, D. J., and Cragg, G. M. (2016). Natural products as sources of new drugs from 1981 to 2014. J. Nat. Prod. 79, 629-661. doi: 10.1021/acs.jnatprod.5b01055

Ochi, K. (2016). Insights into microbial cryptic gene activation and strain improvement: principle, application and technical aspects. J. Antibiot. (Tokyo) 70, 25-40. doi: 10.1038/ja.2016.82

Ohno, S., Katsuyama, Y., Tajima, Y., Izumikawa, M., Takagi, M., Fujie, M., et al. (2015). Identification and characterization of the streptazone E biosynthetic gene cluster in Streptomyces sp. MSC090213JE08. Chembiochem 16, 2385-2391. doi: 10.1002/cbic.201500317

Olano, C., Méndez, C., and Salas, J. A. (2014). "Strategies for the design and discovery of novel antibiotics using genetic engineering and genome mining. Chp. 1," in Antimicrobial Compounds: Actual Strategies and New Alternatives, eds T. G. Villa and P. Veiga-Crespo (Berlin: Springer-Verlag), 1-25. doi: 10. 1007/978-3-642-40444-3_1
Onda, M., Konda, Y., Narimatsu, Y., Omura, S., and Hata, T. (1973). Structure of pyrindicin. Chem. Pharm. Bull. 21, 2048-2050. doi: 10.1248/cpb.21.2048

Pawar, S. V., Ho, J. C., Yadav, G. D., and Yadav, V. G. (2016). The impending renaissance in discovery \& development of natural products. Curr. Top. Med. Chem. doi: 10.2174/1568026616666160530154649 [Epub ahead of print].

Pawlik, K., Kotowska, M., Chater, K. F., Kuczek, K., and Takano, E. (2007). A cryptic type I polyketide synthase (cpk) gene cluster in Streptomyces coelicolor A3(2). Arch. Microbiol. 187, 87-99. doi: 10.1007/s00203-006-0176-7

Peng, H., Wei, E., Wang, J., Zhang, Y., Cheng, L., Ma, H., et al. (2016). Deciphering the piperidine formation in polyketide-derived indolizidines reveals a thioesterreduction, transamination and unusual imine-reduction process. ACS Chem. Biol. 11, 3278-3283. doi: 10.1021/acschembio.6b00875

Prabhu, J., Schauwecker, F., Grammel, N., Keller, U., and Bernhard, M. (2004). Functional expression of the ectoine hydroxylase gene (thpD) from Streptomyces chrysomallus in Halomonas elongate. Appl. Environ. Microbiol. 70, 3130-3132. doi: 10.1128/AEM.70.5.3130-3132.2004

Puder, C., Krastel, P., and Zeeck, A. (2000). Streptazones A, B1, B2, C, and D: new piperidine alkaloids from streptomycetes. J. Nat. Prod. 63, 1258-1260.

Puder, C., Loya, S., Hizi, A., and Zeeck, A. (2001). New co-metabolites of the streptazolin pathway. J. Nat. Prod. 64, 42-45. doi: 10.1021/np000377i

Ramos, J. L., Martinez-Bueno, M., Molina-Henares, A. J., Teran, W., Watanabe, K., Zhang, X., et al. (2005). The TetR family of transcriptional repressors. Microbiol. Mol. Biol. Rev. 69, 326-356. doi: 10.1128/MMBR.69.2.326-356.2005

Rausch, C., Weber, T., Kohlbacher, O., Wohlleben, W., and Huson, D. H. (2005). Specificity prediction of adenylation domains in nonribosomal peptide synthetases (NRPS) using transductive support vector machines (TSVMs). Nucleic Acids Res. 33, 5799-5808. doi: 10.1093/nar/ gki885

Reeves, C. D., Murli, S., Ashley, G. W., Piagentini, M., Hutchinson, C. R., and McDaniel, R. (2001). Alteration of the substrate specificity of a modular polyketide synthase acyltransferase domain through site-specific mutations. Biochemistry 40, 15464-15470. doi: 10.1021/bi015864r

Reid, R., Piagentini, M., Rodríguez, E., Ashley, G., Viswanathan, N., Carney, J., et al. (2003). A model of structure and catalysis for ketoreductase domains in modular polyketide synthases. Biochemistry 42, 72-79. doi: 10.1021/bi0268706

Rodríguez-Mata, M., Frank, A., Wells, E., Leipold, F., Turner, N. J., Hart, S., et al. (2013). Structure and activity of NADPH-dependent Reductase Q1EQE0 from Streptomyces kanamyceticus, which catalyses the R-selective reduction of an imine substrate. Chembiochem 14, 1372-1379. doi: 10.1002/cbic.20130 0321

Rutledge, P. J., and Challis, G. L. (2015). Discovery of microbial natural products by activation of silent biosynthetic gene clusters. Nat. Rev. Microbiol. 13, 509-523. doi: $10.1038 /$ nrmicro3496

Sakagami, Y., Utahara, R., Yagishita, K., and Umezawa, H. (1958). Identity of latumcidin with abikoviromycin. J. Antibiot. (Tokyo) 11, 231-232.

Sambrook, J., and Russell, D. W. (2001). Molecular Cloning: A Laboratory Manual, 3rd Edn. Cold Spring Harbor, NY: Cold Spring Harbor Laboratory.

Sanger, F., Nicklen, S., and Coulson, A. R. (1977). DNA sequencing with chain terminating inhibitors. Proc. Natl. Acad. Sci. U.S.A. 74, 5463-5467. doi: 10.1073/ pnas.74.12.5463

Seipke, R. F., Barke, J., Brearley, C., Hill, L., Yu, D. W., Goss, R. J., et al. (2011). A single Streptomyces symbiont makes multiple antifungals to support the fungus farming ant Acromyrmex octospinosus. PLoS ONE 6:e22028. doi: 10. 1371/journal.pone.0022028

Sultana, A., Kallio, P., Jansson, A., Wang, J. S., Niemi, J., Mäntsälä, P., et al. (2004). Structure of the polyketide cyclase SnoaL reveals a novel mechanism for enzymatic aldol condensation. EMBO J. 23, 1911-1921. doi: 10.1038/sj.emboj. 7600201

Sun, Y., Zhou, X., Liu, J., Bao, K., Zhang, G., Tu, G., et al. (2002). Streptomyces nanchangensis, a producer of the insecticidal polyether antibiotic nanchangmycin and the antiparasitic macrolide meilingmycin, contains multiple polyketide gene clusters. Microbiology 148, 361-371. doi: 10.1099/ 00221287-148-2-361

Tae, H., Kong, E. B., and Park, K. (2007). ASMPKS: an analysis system for modular polyketide synthases. BMC Bioinformatics 8:327. doi: 10.1186/1471-2105-8-327

Takano, H., Obitsu, S., Beppu, T., and Ueda, K. (2005). Light-induced carotenogenesis in Streptomyces coelicolor A3(2): identification of an extracytoplasmic function sigma factor that directs photodependent 
transcription of the carotenoid biosynthesis gene cluster. J. Bacteriol. 187, 1825-1832. doi: 10.1128/JB.187.5.1825-1832.2005

Terashima, T., Kuroda, Y., and Kaneko, Y. (1969). Studies on a new alkaloid of Streptomyces. Struct. Nigrifactin. Tetrahedron Lett. 30, 2535-2537. doi: 10.1016/ S0040-4039(01)88560-9

Terashima, T., Kuroda, Y., and Kaneko, Y. (1970). Studies on alkaloids of Streptomycs. Part II. Pharmacological activity and isolation of nigrifactin and taxonomical studies of Streptomyces strain No. FFD-101. Agr. Biol. Chem. 34, 753-759.

Umezawa, H., Tazaki, T., and Fukuyama, S. (1951). An antiviral substance, abikoviromycin, produced by Streptomyces species. Jpn. J. Med. 4, 331-346. doi: 10.7883/yoken1948.4.331

Vilches, C., Méndez, C., Hardisson, C., and Salas, J. A. (1990). Biosynthesis of oleandomycin by Streptomyces antibioticus: influence of nutritional conditions and development of resistance. J. Gen. Microbiol. 136, 1447-1454. doi: 10.1099/ 00221287-136-8-1447

Weber, T., Blin, K., Duddela, S., Krug, D., Kim, H. U., Bruccoleri, R., et al. (2015). antiSMASH 3.0-a comprehensive resource for the genome mining of biosynthetic gene clusters. Nucleic Acids Res. 43, W237-W243. doi: 10.1093/ nar/gkv437

Weissman, K. J. (2015). Uncovering the structures of modular polyketide synthases. Nat. Prod. Rep. 32, 436-453. doi: 10.1039/c4np00098f

Wietzorrek, A., and Bibb, M. (1997). A novel family of proteins that regulates antibiotic production in streptomycetes appears to contain an OmpR-like DNAbinding fold. Mol. Microbiol. 25, 1181-1184. doi: 10.1046/j.1365-2958.1997. 5421903.x

Xu, W., Qiao, K., and Tang, Y. (2013). Structural analysis of protein-protein interactions in type I polyketide synthases. Crit. Rev. Biochem. Mol. Biol. 48, 98-122. doi: 10.3109/10409238.2012.745476
Yadav, G., Gokhale, R. S., and Mohanty, D. (2003). Computational approach for prediction of domain organization and substrate specificity of modular polyketide synthases. J. Mol. Biol. 328, 335-363. doi: 10.1016/S0022-2836(03) 00232-8

Zabala, D., Braña, A. F., Flórez, A. B., Salas, J. A., and Méndez, C. (2013). Engineering precursor metabolite pools for increasing production of antitumor mithramycins in Streptomyces argillaceus. Metab. Eng. 20, 187-197. doi: 10. 1016/j.ymben.2013.10.002

Zhao, B., Lin, X., Lei, L., Lamb, D. C., Kelly, S. L., Waterman, M. R. et al. (2008). Biosynthesis of the sesquiterpene antibiotic albaflavenone in Streptomyces coelicolor A3(2). J. Biol. Chem. 283, 8183-8189. doi: 10.1021/ja901 $313 \mathrm{v}$

Conflict of Interest Statement: The authors declare that the research was conducted in the absence of any commercial or financial relationships that could be construed as a potential conflict of interest.

The reviewer MN and handling Editor declared their shared affiliation, and the handling Editor states that the process nevertheless met the standards of a fair and objective review.

Copyright (c) 2017 Ye, Molloy, Braña, Zabala, Olano, Cortés, Morís, Salas and Méndez. This is an open-access article distributed under the terms of the Creative Commons Attribution License (CC BY). The use, distribution or reproduction in other forums is permitted, provided the original author(s) or licensor are credited and that the original publication in this journal is cited, in accordance with accepted academic practice. No use, distribution or reproduction is permitted which does not comply with these terms. 